\title{
Vivian Colucci
}

\section{DESMINERALIZAÇÃo do ESMALTE DENTAL ADJACENTE A RESTAURAÇÕES. EFEITO DOS PARÂMETROS DO LASER DE ER:YAG EMPREGADO PARA O PREPARO CAVITÁRIO}

Tese apresentada à Faculdade de Odontologia de Ribeirão Preto da Universidade de São Paulo, para obtenção de título de Doutor em Odontologia Restauradora

Área de Concentração: Dentística

Orientadora: Profa. Dra. Silmara Aparecida Milori Corona

Ribeirão Preto

2010 
AUTORIZO A REPRODUÇÃO E DIVULGAÇÃO TOTAL OU PARCIAL DESTE TRABALHO, POR QUALQUER MEIO CONVENCIONAL OU ELETRÔNICO, PARA FINS DE ESTUDO E PESQUISA, DESDE QUE CITADA A FONTE.

FICHA CATALOGRÁFICA

\section{Colucci, Vivian}

Desmineralização do esmalte dental adjacente a restaurações. Efeito dos parâmetros do laser de Er:YAG empregado para o preparo cavitário / Vivian Colucci; Orientadora Silmara Aparecida Milori Corona. - Ribeirão Preto, 2010.

73p.: il.; $30 \mathrm{~cm}$

Tese (Doutorado - Programa de Pós-graduação em Odontologia Restauradora. Área de Concentração: Dentística)

- Faculdade de Odontologia de Ribeirão Preto/USP

1. Esmalte dental; 2. Desmineralização; 3. Cárie; 4. Preparo cavitário; 5.Laser de Er:YAG 


\section{FOLHA DE APROVAÇÃO}

Nome: COLUCCI, Vivian

Título: Desmineralização do esmalte dental adjacente a restaurações. Efeito dos parâmetros do laser de Er:YAG empregado para o preparo cavitário.

Tese apresentada à Faculdade de Odontologia de Ribeirão Preto da Universidade de São Paulo, para obtenção de título de Doutor em Odontologia Restauradora

Aprovada em:

\section{Banca Examinadora}

Prof (a). Dr (a).

Instituição:

Julgamento:

Assinatura:

Prof (a). Dr (a).

Instituição:

Julgamento:

Assinatura:

Prof (a). Dr (a).

Instituição:

Julgamento:

Assinatura:

Prof (a). Dr (a).

Instituição:

Julgamento:

Assinatura:

Prof (a). Dr (a).

Instituição:

Julgamento:

Assinatura: 
Dedicatória 


\title{
DEDICO ESTE TRABALHO...
}

À minha família, com enorme gratidão.

\begin{abstract}
"A Família não nasce pronta; constrói-se aos poucos, e éo melhor laboratório do amor. Em casa, entre pais e filhos, podese aprender a amar, pode-se experimentar com profundidade a grande aventura de amar sem medo. A família pode ser o ambiente mais apropriado para uma maravilhosa experiência de amor"
\end{abstract}

Mazenildo Feliciano Pereira

À Luísa, que muito mais do que filha é hoje minha razão de viver.

"Presente para toda vida, nunca mais solidão!

Anjinho abençoado, pureza de coração.

Linda jóia rara, razão do meu viver.

Quero viver repetindo: - Eu amo amar você!”

Autor desconhecido

Ao Miltinho, por acreditar em mim, pelo apoio incondicional às minhas escolhas, pelo irrestrito companheirismo e pelos momentos de abstração e cuidados com a Luísa, que foram indispensáveis para a realização deste trabalho.

"'Para conquistarmos algo na vida não basta ter talento, não basta ter força, é preciso também viver um grande amor".

Mozart 


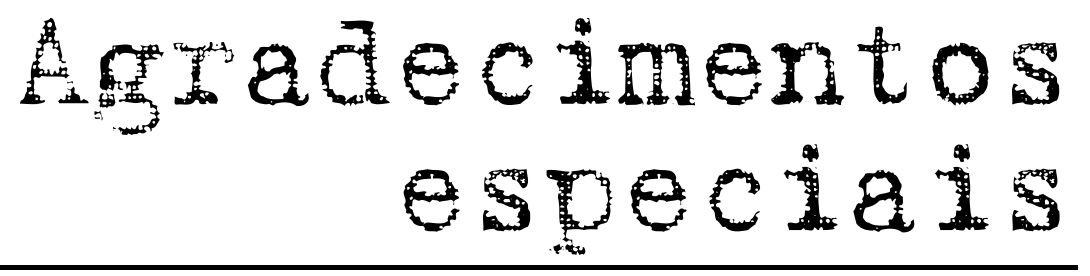


A Deus, por conduzir a minha vida.

À Profa. Dra. Silmara Aparecida Milori Corona, por sua atenção, carinho e amizade. Simplesmente, um exemplo a ser seguido. Gostaria de um dia conseguir refletir o que você representa para mim, modelo de MÃE e MESTRE. Obrigada pela paciência, disposição, ternura e bom-humor com os quais você sempre conduz nossos trabalhos. Agradeço a Deus por tê-la conhecido e por você fazer parte da minha vida.

À Profa. Dra. Regina Guenka Palma Dibb, pela orientação para idealização deste trabalho, pelos ensinamentos transmitidos ao longo dos anos e pelo auxílio na irradiação dos espécimes do estudo in vitro.

À Profa. Dra. Mônica Campos Serra, pelos conhecimentos transmitidos, pelo auxílio nas horas de dificuldade e compartilhamento dos momentos de alegria.

Às minhas amigas, Juliane, Alê, Aline, Cris, Flávia, Dani, Ciça e Michelinha:

"AMIZADE, o mais nobre dos sentimentos. Cresce à sombra do desinteresse, Nutre-se brindando-se e floresce a cada dia com a compreensão. Seu lugar está junto ao amor, porque ela é também amor. Somente os honestos podem ter amigos, porque à amizade, o mais leve dos cálculos a fere. Como é um bem reservado aos eleitos, é o sentimento mais incompreendido e o pior interpretado. Não admite sombras nem fingimentos, rusticidade nem renúncias. Exige no entanto sacrifício e coragem, compreensão e verdade, VERDADE! acima de todas as coisas." 
Agradecimentos 
À Universidade de São Paulo, representada pela Magnífica Reitora Profa. Dra. Suely Vilela.

À Faculdade de Odontologia de Ribeirão Preto - USP, representada pelo seu Diretor Prof. Dr. Osvaldo Luiz Bezzon.

À Presidente da Comissão de Pós-graduação da Faculdade de Odontologia de Ribeirão Preto-USP, Profa. Dra. Léa Assed Bezerra da Silva.

À Coordenação do Curso de Pós-Graduação em Odontologia Restauradora da Faculdade de Odontologia de Ribeirão Preto da Universidade de São Paulo, na pessoa do Prof. Dr. Manoel Damião de Souza Neto.

À FAPESP, pelo apoio financeiro concedido para a execução deste trabalho.

Aos Professores do Departamento de Odontologia Restauradora da Faculdade de Odontologia de Ribeirão Preto - USP, pela expressiva contribuição para meu desenvolvimento acadêmico - científico.

Às Profa. Dra. Alma Blásida Concepción Elizaur Benitez Catirse, Profa. Dra. Valéria Oliveira Pagnano de Souza e Profa. Dra. Andréa Cândido dos Reis, pelos conselhos, por incentivarem a busca pelos meus sonhos e por mostrarem aos seus alunos o lado humano da pós-graduação.

À Patrícia Marchi, técnica do laboratório de Dentística da Faculdade de Odontologia de Ribeirão Preto - USP, pela solicitude e disponibilidade para ajudar sempre.

Ao Prof. Dr. Jesus Djalma Pécora do Departamento de Odontologia Restauradora da Faculdade de Odontologia de Ribeirão Preto - USP, pela disponibilização do laser de Er:YAG e ao técnico Reginaldo Santana da Silva, pelo auxílio durante a utilização do equipamento e pela amizade.

À Profa. Dra. Raquel Fernanda Gerlach do Departamento de Morfologia e Estomatologia da Faculdade de Odontogia de Ribeirão Preto - USP e à Profa. Dra. 
Helena de Freitas Oliveira Paranhos do Departamento de Materiais Dentários e Prótese da Faculdade de Odontogia de Ribeirão Preto - USP, pela disponibilização dos microscópios de luz polarizada.

À Carol, Junia e Ana Paula, pelo auxílio com a utilização do microscópio de luz polarizada.

Ao Prof. Dr. Antonio Luiz Rodrigues Júnior do Departamento de Medicina Social da Faculdade de Medicina de Ribeirão Preto - USP, pelo auxílio com a análise estatística.

Ao setor de esterilização com óxido de etileno do Hospital das Clínicas da Faculdade de Medicina de Ribeirão Preto - USP.

Ao Carlos, secretário do Curso de Pós-Graduação em Odontologia Restauradora da Faculdade de Odontologia de Ribeirão Preto da Universidade de São Paulo, pela eficiência e rapidez na solução dos nossos problemas e, sobretudo, pela amizade.

Às funcionárias da Seção de Pós-Graduação da Faculdade de Odontologia de Ribeirão Preto - USP, Isabel e Regiane.

Às funcionárias do Departamento de Odontologia Restauradora, Rosângela e Luiza.

Aos amigos e orientados da Profa. Silmara, Daniel, Cris Rocha, Taísa, Sandra, Adrielly, Rodrigo, pela amizade e pelas trocas de conhecimento indispensáveis para o crescimento de uma equipe.

Aos amigos e voluntários da pesquisa in situ Daniele, Vinícius, César, Talitha, Taísa, Sandra, Daniel, Adrielly, Carol, Bruninha, Ana, Fer, Carol e Dani.

Aos amigos e companheiros de pós-graduação do Departamento de Odontologia Restauradora, Odontopediatria e Reabilitação Oral.

À Amália e Bel, secretárias do Departamento de Odontologia Restauradora da Faculdade de Odontologia de Ribeirão Preto - USP, pela amizade e atenção dispensada. 
A todos aqueles que de alguma forma contribuíram para a realização deste trabalho. 


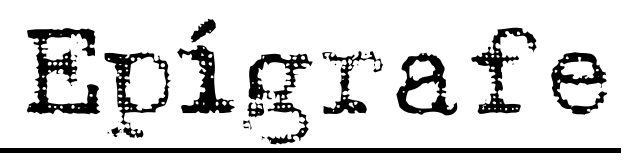


"A vida está cheia de desafios que, se aproveitados de forma criativa, transformam-se em oportunidades"

(Maxwell Maltz) 


\section{SUMÁRIO}

REsumo

ABstRact

1. INTRODUÇÃO

2. ProposiçÃo 25

3. Material e Método

3.1 Estudo in vitro 27

3.2 Estudo in situ 34

4. Resultados

4.1 Estudo in vitro 41

4.2 Estudo in situ 48

5. DiscussÃo 54

6. Conclusões 61

7. REFERÊnCIAS BIBLIOGRÁFICAS 63 


\section{RESUMO}

COLUCCI, V. Desmineralização do esmalte dental adjacente a restaurações. Efeito dos parâmetros do laser de Er:YAG empregado para o preparo cavitário. 2010. $73 f$. Tese (Doutorado) - Faculdade de Odontologia de Ribeirão Preto, Universidade de São Paulo, Ribeirão Preto, 2010.

O presente estudo, composto por dois experimentos, teve como objetivo avaliar in vitro o efeito de parâmetros do laser de Er:YAG na desmineralização do esmalte dental humano e bovino após desafio cariogênico e avaliar, através de um modelo in situ, o efeito de diferentes parâmetros do laser de Er:YAG no desenvolvimento de lesões de cárie adjacente a restaurações. No estudo in vitro, terceiros molares inclusos humanos hígidos e incisivos bovinos foram seccionados para a seleção de 50 fragmentos de cada um dos substratos, que foram aleatoriamente divididos em 10 grupos, sendo 9 experimentais preparados com laser de Er:YAG com $300 \mathrm{~mJ}$ de energia (frequência de $2 \mathrm{~Hz}, 4 \mathrm{~Hz}$ ou $6 \mathrm{~Hz}$, fluxo de água de $2,0 \mathrm{~mL} / \mathrm{min}, 5,0 \mathrm{~mL} / \mathrm{min}$ ou $8,0 \mathrm{~mL} / \mathrm{min}$ ) e 1 controle (turbina de alta rotação). Após o preparo das cavidades, os espécimes foram restaurados com resina composta e submetidos ao desafio cariogênico. Subseqüentemente, foram seccionados para a análise da microdureza e realização de microscopia de luz polarizada qualitativa. No estudo in situ, 150 fragmentos de esmalte bovino foram distribuídos aleatoriamente entre 15 voluntários. Tais fragmentos foram subdivididos em 10 grupos conforme descrito para o estudo in vitro. Os 9 grupos experimentais foram preparados com laser de Er:YAG empregando-se diferentes combinações de parâmetros, conforme descrito pra o estudo in vitro. O grupo controle foi preparado com turbina de alta-rotação e ponta diamantada. A cavidade obtida foi restaurada com resina composta e os fragmentos foram montados em dispositivo palatino para serem instalados nos voluntários participantes para a realização do desafio cariogênico. Após o desafio, os espécimes foram seccionados para a realização das leituras de microdureza longitudinal e microscopia de luz polarizada qualitativa. Os dados obtidos no ensaio de microdureza foram analisados estatisticamente. Para o estudo in vitro foi realizada a Análise de variância e o teste de Tukey e observou-se que, independentemente do substrato testado, os espécimes preparados com turbina de alta rotação 
apresentaram menores médias de microdureza que os preparados com laser de Er:YAG para todos os parâmetros testados, os quais foram semelhantes entre si $(p>0,05)$. As imagens de microscopia de luz polarizada demonstraram uma tendência dos grupos irradiados com laser de Er:YAG com uma freqüência de $2 \mathrm{~Hz}$ apresentarem menor desmineralização. Para o estudo in situ foi realizado teste de Friedman que demonstrou haver diferença estatística entre os métodos de preparo cavitário empregados com relação as medidas de microdureza. Para identificar as diferenças entre os grupos foi realizado o teste de Wilcoxon pareado e observouse que o grupo preparado com laser de Er:YAG com $2 \mathrm{~Hz}$ de freqüência e $2 \mathrm{~mL} / \mathrm{min}$ de fluxo de água apresentou a maiores médias de microdureza, seguido por aqueles preparados com laser de Er:YAG com $2 \mathrm{~Hz}$ de freqüência e $5 \mathrm{~mL} / \mathrm{min}$ de fluxo de água e laser de Er:YAG com $2 \mathrm{~Hz}$ de freqüência e $8 \mathrm{~mL} / \mathrm{min}$ de fluxo de água, respectivamente. Os grupos preparados com laser de Er:YAG com as freqüências de $4 \mathrm{~Hz}$ e $6 \mathrm{~Hz}$, com fluxos de água de 2, 5 e $8 \mathrm{~mL} / \mathrm{min}$ apresentaram médias de microdureza menores que os grupos supracitados e com similaridade estatística entre si. Todos os grupos preparados com laser de Er:YAG demonstraram médias de microdureza superiores àquele preparado com turbina de alta-rotação, o qual apresentou as menores médias de microdureza. As imagens de microscopia de luz polarizada confirmaram os resultados obtidos com o ensaio de microdureza. Assim, pode-se concluir que o substrato bovino constitui uma alternativa ao substrato humano em estudos que avaliem o laser de Er:YAG e a progressão de lesões de cárie, que o laser de Er:YAG foi capaz de controlar o desenvolvimento de lesões de cárie adjacente a restaurações de resina composta e que o conjunto de parâmetros empregados para o preparo cavitário pode influenciar na resistência ácida do substrato irradiado.

Palavras-chave: Esmalte dental. Desmineralização. Cárie. Preparo cavitário. Laser de Er:YAG. 


\section{ABSTRACT}

COLUCCI, V. Enamel demineralization around dental restoration. Effect of Er:YAG laser parameters employed to cavity preparation. 2010. 73f. Thesis (Doctoral - Faculdade de Odontologia de Ribeirão Preto, Universidade de São Paulo, Ribeirão Preto, 2010.

The current study, composed by two experiments, sought to evaluate in vitro the effect of Er:YAG laser parameters on human and bovine enamel demineralization after cariogenic challenges and to check, through an in situ model, the effect of different Er:YAG laser parameters on development of carieslike lesions adjacent to dental restorations. In the in vitro study, sound human third molars and bovine incisors were cut to select 50 specimens of each substrate, which were randomly allocated into 10 groups: 9 experimental groups prepared with Er:YAG laser with $300 \mathrm{~mJ}$ output (frequency of $2 \mathrm{~Hz}, 4 \mathrm{~Hz}$ or $6 \mathrm{~Hz}$, water flow rate of $2.0 \mathrm{~mL} / \mathrm{min}, 5.0 \mathrm{~mL} / \mathrm{min}$ or $8.0 \mathrm{~mL} / \mathrm{min}$ ) and 1 control group (High speed handpiece). After cavity preparation, the specimens were restored with composite resin and submitted to the cariogenic challenge. Afterwards, they were sectioned to obtain the microhardness measurements and images of light polarized microscopy. In the in situ study, 150 bovine enamel slabs were randomly allocated among 15 volunteers. These specimens were subdivided into 10 groups, as described above to the in vitro study. 9 experimental groups were prepared with Er:YAG laser under different parameters combination. The control group was prepared with high speed handpiece associated to a diamond bur. The prepared cavity was restored with a composite resin and the slabs were mounted on palatal appliance to be installed in the volunteers to the realization of the cariogenic challenge. After this, the specimens were sectioned to the longitudinal microhardness measurements and to the qualitative light polarized microscopy. The data obtained by means of microhardness test were statistically analyzed. For the in vitro study was performed Analisys of Variance and Tukey's test, which demonstrated that, regardless the tested substrate, the specimens prepared with high speed handpiece showed lower microhardness means than those prepared with the Er:YAG laser for all 
tested parameters, which were statistically similar $(p>0,05)$. The light polarized microscopy images demonstrated that the groups irradiated with Er:YAG laser with $2 \mathrm{~Hz}$ frequency showed a tendency to be less susceptible to the demineralization. For the in situ study was performed the Friedman test, which demonstrated that there are statistical difference among the cavity preparation methods according to the microhardness measurements. To indentify the differences among groups it was performed the Wilcoxon paread test and it was observed that the group prepared with Er:YAG laser with $2 \mathrm{~Hz}$ of frequency and $2.0 \mathrm{~mL} / \mathrm{min}$ of water flow rate showed the highest microhardness means, followed by that prepared with Er:YAG laser with $2 \mathrm{~Hz}$ of frequency and $5.0 \mathrm{~mL} / \mathrm{min}$ of water flow rate and $\mathrm{Er}: Y A G$ laser with $2 \mathrm{~Hz}$ of frequency and $8.0 \mathrm{~mL} / \mathrm{min}$ of water flow rate, respectively. The groups prepared with Er:YAG laser with $4 \mathrm{~Hz}$ and $6 \mathrm{~Hz}$ of frequency, with water flow rates of $2.0,5.0$ and $8.0 \mathrm{~mL} / \mathrm{min}$ showed microhardness means lower than the groups cited above and statistical similarity among them. All groups prepared with Er:YAG laser demonstrated microhardness means higher than that prepared with high speed handpiece, what showed the lowest microhardness means. The light polarized microscopy images confirmed the results obtained with the microhardness test. Thus, it may be concluded that the bovine substrate constitutes an alternative to the human substrate in studies that evaluates the Er:YAG laser and caries-like lesions progression, that the Er:YAG laser was capable to control the development of caries-like lesions around composite resin restorations and that the parameters employed to the cavity preparation could influence on acid resistance of the irradiated substrate.

Keywords: Dental enamel. Demineralization. Caries. Cavity preparation. Er:YAG laser. 
Introdução 


\section{INTRODUÇÃO}

A cárie dental é uma doença multifatorial e transmissível, causada por ácidos advindos do metabolismo bacteriano que se difundem através dos tecidos dentais, dissolvendo-os (FEATHERSTONE, 2008). Inicialmente, bactérias colonizam a película adquirida do esmalte e fermentam carboidratos disponíveis, levando à formação de ácidos orgânicos, incluindo ácido lático, fórmico, acético e propiônico (FEATHERSTONE, 2000), que promovem diminuição do $\mathrm{pH}$ da cavidade oral (FEATHERSTONE; RODGERS, 1981). A queda no $\mathrm{pH}$ torna o meio oral insaturado em relação ao dente o que faz com que haja perda de íons dos tecidos dentais para o meio. Com a concentração de íons no meio bucal ocorre o aumento do $\mathrm{pH}$ que promove o retorno dos íons do fluido oral para os tecidos dentais (FEATHERSTONE, 2000).

A progressão da lesão de cárie é um processo amplamente dinâmico, caracterizado por períodos de dissolução e re-deposição de minerais nos tecidos dentais duros (FEATHERSTONE, 2008). Assim, os tecidos dentais são submetidos continuamente a ciclos de desmineralização que apresenta períodos nos quais o $\mathrm{pH}$ apresenta-se abaixo do crítico, seguido por períodos de aumento do $\mathrm{pH}$, quando há condições favoráveis à remineralização (ZERO, 1999). A alternância entre ciclos de des e remineralização perduram na cavidade bucal tanto quanto co-existirem bactérias cariogências, carboidratos fermentáveis e saliva (FEATHERSTONE, 2008). Estes ciclos promovem flutuação dos níveis de minerais dos tecidos dentais ao longo do tempo (ZERO, 1999) e quando há predomínio da perda de minerais, a lesão de cárie se desenvolve e progride, culminado com a formação da cavidade (FEATHERSTONE, 2004; FEATHERSTONE, 2008).

À medida que a lesão de cárie progride, pode haver a necessidade de se instituir medidas restauradoras, com intuito de se restituir a forma e a função dos tecidos dentais perdidos. Entretanto, a instituição do tratamento restaurador não garante o controle da doença (MALTZ; CARVALHO, 1999). Se as flutuações de $\mathrm{pH}$ forem mantidas, novas lesões podem se desenvolver ao redor das restaurações.

O diagnóstico clínico de lesões de cárie secundária apresenta-se como a principal razão apontada para a substituição de todos os tipos de restaurações diretas (KLAUSNER; GREEN; CHARBENEAU, 1987; MJÖR; MOORHEAD; 
DAHL, 2000; MJÖR, 2005; SARRETT, 2005) representando de 50 a $60 \%$ de todas as substituições (MJÖR; GORDAN, 2002). A durabilidade limitada das restaurações dentais coloca pacientes em ciclos restauradores repetitivos (ELDERTON, 2003) responsáveis por tornar a terapia requerida mais complexa e desgastar cada vez mais a estrutura dental (BRANTLEY et al., 1995). Dessa forma, prevenir ou retardar o desenvolvimento destas lesões poderia reduzir a substituição de restaurações, minimizando-se assim a necessidade por tratamentos resturadores e custos adicionais (KLEIN et al., 2005).

A estrutura dental adjacente a restaurações é bastante susceptível ao desenvolvimento de lesões de cárie em decorrência da imperfeita adaptação da interface dente/restauração (STANINEC et al., 1985; KIDD; TOFFENETTI, 1992). Assim, a busca pela identificação de métodos capazes de prevenir ou retardar o desenvolvimento de lesões de cárie adjacente a restaurações que, conseqüentemente, aumentem a durabilidade clínica das mesmas tem sido intensificada e novas tecnologias têm sido estudadas.

A irradiação com laser de Er:YAG tem sido proposta como técnica alternativa para a remoção de lesões de cárie (AOKI et al., 1998; EBERHARD et al., 2008; MATSUMOTO et al., 2007; KRAUSE et al., 2008; KORNBLIT et al., 2008; JEPSEN et al., 2008), preparo cavitário (MATSUMOTO et al., 1996; CORONA et al., 2001; SCHEIN et al., 2003; MATSUMOTO et al., 2007), remoção de materiais restauradores estéticos (LIZARELLI; MORIYAMA; BAGNATO, 2003; CORRÊA-AFONSO; PÉCORA; PALMA-DIBB, 2008; CORRÊA-AFONSO; PALMA-DIBB; PÉCORA, 2010) e condicionamento da superfície dental (VISURI et al., 1996; CEBALLOS et al., 2001) com o objetivo de minimizar o desconforto dos pacientes durante o tratamento, por meio da diminuição do ruído, pressão e dor (HIBST et al., 2002) eliminando, na maioria dos casos, a necessidade de anestesia local (PELAGALLI et al., 1997; KELLER; HIBST, 1989), além de preservar ao máximo a estrutura dental sadia (HIBST; KELLER, 1989; BURKES et al., 1992).

O laser de Er:YAG demonstra elevada eficiência na ablação dos tecidos dentais, uma vez que seu comprimento de onda $(2,94 \mu \mathrm{m})$ é altamente absorvido pela água e relativamente bem absorvido pelos íons hidroxila $\left(\mathrm{OH}^{-}\right)$ da hidroxiapatita (AOKI et al., 1998; HOSSAIN et al., 2000), cujos picos de absorção estão em torno de $3 \mu \mathrm{m}$ e 2,8 $\mu \mathrm{m}$ respectivamente (APEL et al., 
2002). Somado a isso, tem sido demonstrado que a irradiação do esmalte dental com laser de Er:YAG, tanto com parâmetros ablativos quanto subablativos, promove $\mathrm{o}$ aumento da resistência do esmalte frente à desmineralização (CECCHINI et al., 2005; KNOW et al., 2005; HOSSAIN et al., 2000; CEBALLOS et al., 2003; PERITO et al., 2009).

A irradiação dos tecidos dentais com diversos tipos de laser leva a alterações químicas e ultraestruturais do esmalte (CECCHINI et al., 2003; SILVA-TAGLIAFERRO et al., 2009) e da dentina (MATSUMOTO et al., 2003; BACHMANN et al., 2005), vinculadas ao aumento da temperatura na área de irradiação. Assim, a interação do laser com os tecidos-alvo, modulada pelo conjunto de parâmetros empregados para a irradiação poderia interferir, positiva ou negativamente, nas alterações ocorridas no substrato.

A eficiência do processo de ablação, bem como a geração de calor, apresenta-se associada à freqüência de pulsos e densidade de energia empregada na irradiação com laser de Er:YAG. O aumento da taxa de repetição de pulsos por segundo e da densidade de energia promove maior liberação de calor (KELLER \& HIBST, 1995; GERALDO-MARTINS et al., 2005) e parte deste resulta em deposição de calor residual (FRIED; RAGADIO; CHAMPION, 2001), o que pode levar a diferentes alterações químicas, estruturais e morfológicas da superfície do esmalte e, desta forma, prejudicar ou favorecer a resistência dos tecidos irradiados a desmineralização.

Associado a isso, a utilização de um fluxo de água constante ajustado aos parâmetros empregados durante a irradiação do substrato, favorece 0 processo de ablação (KIM; JEOUNG; KIM, 2003; COLUCCl et al., 2008; COLUCCI et al., 2009; COLUCCI et al., 2010) e protege os tecidos dentais de possíveis danos térmicos (CAVALCANTI; LAGE-MARQUES; RODE, 2003; GERALDO-MARTINS et al., 2005). Tem sido observado que o aumento da resistência do esmalte a desmineralização promovido pelo laser de Er:YAG mostra-se efetivo tanto quando este é empregado sob refrigeração quanto sem refrigeração (HOSSAIN et al., 2000). Quando empregado sob refrigeração, a proteção do esmalte contra desafios ácidos é menor (HOSSAIN et al., 2000). Contudo, estudos relacionados à variação de temperatura mostram que 0 emprego do laser sem refrigeração promove temperaturas residuais acima de $5,5^{\circ} \mathrm{C}$, proposto como limite de segurança para a vitalidade pulpar $(\mathrm{ZACH}$; 
COHEN, 1965), o que torna o emprego do fluxo de água clinicamente indispensável (DOSTALOVÁ et al., 1996). Além disso, a irradiação sem refrigeração leva à desidratação dos tecidos, reduzindo ou até mesmo paralisando o processo de ablação (APEL; SCHÄFER; GUTKNECHT, 2003).

Modelos in vitro (CAIN et al., 2006; THOMAZ et al., 2006; WESTERMAN et al., 2006; PERITO et al., 2009) e in situ (LAJERWEIJI; TEN CATE, 2006; APEL et al., 2005; CHIMELLO-SOUZA et al., 2008; CHIMELLO-SOUZA et al., 2009) têm sido empregados para avaliar a formação e a progressão de lesões de cárie. Entretanto, algumas variáveis experimentais têm sido observadas, como o tipo de substrato dental empregado (HARA et al., 2003; CAIN et al., 2006). A vantagem de se utilizar dentes bovinos é que, além dos aspectos éticos envolvidos, são de fácil obtenção e manipulação quando comparados aos humanos (MELLBERG, 1992). Além disso, o dente bovino apresenta menor variabilidade se comparado com o humano. Dessa forma, os resultados obtidos em experimentos realizados com substrato bovino apresentam uma resposta experimental mais consistente (MELLBERG, 1992). Ainda, os dentes bovinos apresentam anatomia mais favorável para a obtenção dos fragmentos de teste, com concentração de flúor na superfície inferior àquela encontrada nos dentes humanos (MELLBERG; LOERTSCHER, 1974) e não foram submetidos previamente a desafios cariogênicos, o que poderia afetar os futuros resultados (MELLBERG, 1992). Apesar de o esmalte bovino ser mais poroso que o humano, sugere-se que existe apenas diferença quantitativa e não qualitativa entre ambos (MELLBERG, 1992; ZERO, 1995; SOUZAGABRIEL et al., 2010).

Desse modo, o emprego do esmalte bovino tem sido aceito para avaliar o potencial cariogênico ou anti-cariogênico das substâncias e tratamentos (MELLBERG, 1992). Por outro lado, não há disponível na literatura nenhum estudo que avalie a influência da irradiação com laser de Er:YAG no esmalte humano e bovino submetido à desafio cariogênico.

Assim, justifica-se a busca pela validação do emprego do substrato bovino em substituição ao humano em estudos que empreguem laser de Er:YAG, e também a obtenção de um conjunto de parâmetros, incluindo a frequência de pulsos e o fluxo que água, que seja capaz de promover 
resistência à desmineralização do esmalte dental adjacente a restaurações, além de garantir segurança aos tecidos dentais irradiados. 
Proposição 


\section{PROPOSIÇÃO}

O presente estudo, composto por dois experimentos, teve como objetivo geral avaliar o efeito dos parâmetros do laser de Er:YAG empregado para o preparo cavitário na desmineralização do esmalte dental adjacente a restaurações. Os objetivos específicos foram:

1) Avaliar o efeito dos parâmetros (freqüência de pulsos e fluxo de água) do laser de Er:YAG na desmineralização do esmalte dental, humano e bovino, submetido a desafio cariogênico in vitro.

2) Avaliar, através de um modelo in situ, o efeito de diferentes parâmetros (freqüência de pulsos e fluxo de água) do laser de Er:YAG empregado para o preparo cavitário no desenvolvimento de lesões de cárie adjacente a restaurações. 
Materiais e Métodos 


\section{MATERIAIS E MÉTODOS}

\section{Aspectos Éticos}

O presente estudo foi submetido ao Comitê de Ética em Pesquisa da FORP/USP que deliberou aprová-lo (CAAE 0048.0.138.000-06).

\section{Estudo in vitro}

\section{Delineamento Experimental}

Os fatores em estudo foram Preparo cavitário em 10 níveis, sendo 9 experimentais (I - Laser de Er:YAG - 300mJ/2Hz, 2,0mL/min; II - Laser de Er:YAG - 300mJ/4Hz, 2,0mL/min; III - Laser de Er:YAG - 300mJ/6Hz, 2,0mL/min; IV - Laser de Er:YAG - 300mJ/2Hz, 5,0mL/min; V - Laser de Er:YAG - 300mJ/4Hz, 5,0mL/min; VI - Laser de Er:YAG - 300mJ/6Hz, 5,0mL/min; VII - Laser de Er:YAG - 300mJ/2Hz, 8,0mL/min; VIII - Laser de Er:YAG - 300mJ/4Hz, 8,0mL/min; IX - Laser de Er:YAG - 300mJ/6Hz, $8,0 \mathrm{~mL} / \mathrm{min}$ ) e 1 controle (X - turbina de alta rotação) e Substrato em 2 níveis (esmalte humano e esmalte bovino). A amostra do experimento foi composta por 100 fragmentos de esmalte (50 humanos e 50 bovinos), que foram divididos aleatoriamente nos 10 grupos $(n=5)$. O delineamento experimental adotado foi o de blocos completos casualizados.

\section{Seleção dos dentes}

Para a realização deste trabalho, foram utilizados terceiros molares humanos inclusos hígidos e incisivos bovinos mantidos em solução de formol à temperatura de $4^{\circ} \mathrm{C}$ (DOMINICl et al., 2001), que foram limpos com o auxílio de pedra pomes e água com escovas de Robinson e examinados através de estéreo-microscópio (Leica S6 D Stereozoom, Leica Mycrosystems AG, Suiça) com aumento de 40X, descartando-se aqueles com trincas ou anomalias de estrutura.

\section{Preparo dos fragmentos}

Os dentes tiveram suas raízes removidas $2 \mathrm{~mm}$ abaixo da junção amelocementária com um disco diamantado (15HC, Buehler, Alemanha) montado em cortadeira elétrica de precisão (Isomet 1000, Buehler, Alemanha). Posteriormente, as coroas dos dentes humanos foram seccionadas nos 
sentidos mésio-distal e vestíbulo-lingual, de forma a obter quatro secções por dente. Os dentes bovinos foram seccionados no sentido mésio-distal e cérvicoincisal, de modo a se obter quatro secções por dente. Cada um dos fragmentos foi novamente submetido à máquina de corte para se obter dimensões de $4 \times 3 \mathrm{~mm}$, as quais foram checadas com auxílio de um paquímetro digital (Mitutoyo Sul-americana, Suzano, Brasil) (Figura 1).

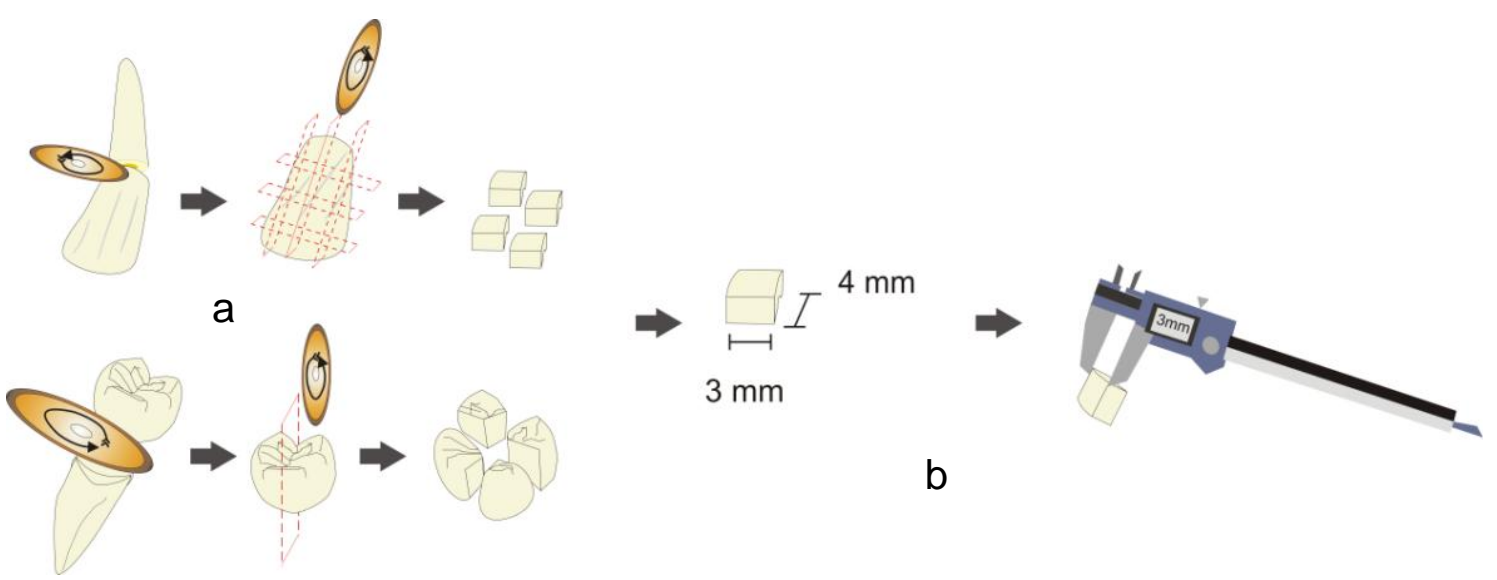

Figura 1 - a. Secção dos dentes para obtenção dos fragmentos de esmalte; b. Aferição das dimensões dos espécimes

\section{Seleção dos fragmentos}

Os espécimes foram fixados com cera em suportes de resina acrília e tiveram suas superfícies laterais polidas em Politriz giratória (Phoelix $\beta$, Buehler, Alemanha) refrigerada à água (HARA et al., 2003). Foram realizadas três leituras de microdureza na lateral dos fragmentos distantes $30 \mu \mathrm{m}$ da superfície e a $100 \mu \mathrm{m}$ uma da outra, estabelecendo-se uma dureza média que permitiu a seleção dos espécimes (HARA et al., 2006) (Figura 2). Foram selecionados fragmentos de esmalte humano e bovino com dureza média de $330 \mathrm{KHN}$.

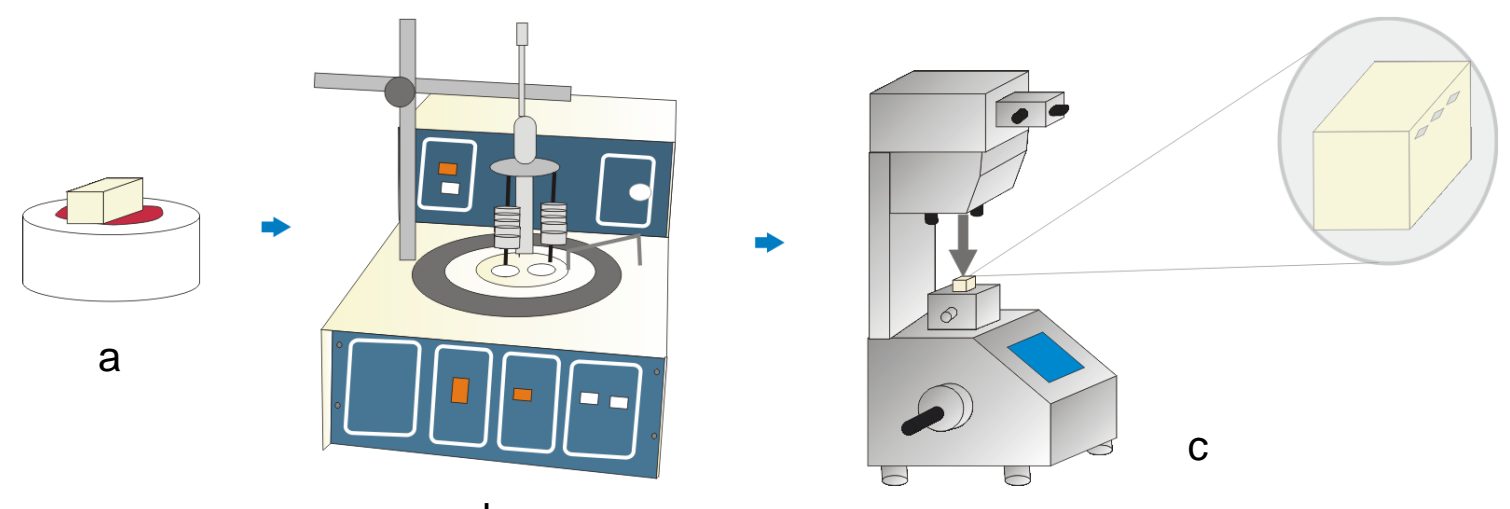

b

Figura 2 - a. Fixação dos espécimes com cera em suportes de resina acrílica; b. Polimento das superfícies lateriais dos espécimes; c. Seleção dos espécimes 


\section{Preparo Cavitário}

Os fragmentos de esmalte bovino e humano foram divididos aleatoriamente entre os grupos de acordo com o preparo cavitário: I - Laser de Er:YAG - 300mJ/2Hz, 2,0mL/min; II - Laser de Er:YAG - $300 \mathrm{~mJ} / 4 \mathrm{~Hz}$, 2,0mL/min; III - Laser de Er:YAG - 300mJ/6Hz, 2,0mL/min; IV - Laser de Er:YAG - 300mJ/2Hz, 5,0mL/min; V - Laser de Er:YAG - $300 \mathrm{~mJ} / 4 \mathrm{~Hz}$, 5,0mL/min; VI - Laser de Er:YAG - 300mJ/6Hz, 5,0mL/min; VII - Laser de Er:YAG - 300mJ/2Hz, 8,0mL/min; VIII - Laser de Er:YAG - $300 \mathrm{~mJ} / 4 \mathrm{~Hz}$, 8,0mL/min; IX - Laser de Er:YAG - 300mJ $6 \mathrm{~Hz}, 8,0 \mathrm{~mL} / \mathrm{min}$ e X- turbina de alta rotação. Em cada um dos fragmentos foi delimitada uma área de $3 \times 1 \mathrm{~mm}$ para padronizar o preparo cavitário. O laser de Er:YAG (Kavo Key II, Kavo Dental GmbH \& Co.KG, 88396, Biberach, Alemanha) foi empregado até que se obtivesse uma cavidade com profundidade média de $1 \mathrm{~mm}$, a qual era checada com auxílio de uma sonda peridontal.

A aplicação do laser de Er:YAG foi realizada no modo não-contato, focado a uma distância de $12 \mathrm{~mm}$ do substrato (CHIMELLO-SOUZA et al., 2006), empregando-se um dispositivo que promove a fixação da caneta do laser (Figura 3). Os espécimes foram posicionados em uma base que se movimenta nos eixos $x$ e y. $O$ spray de água/ar foi ativado e a regulagem do fluxo de água para a refrigeração do tecido dental foi ajustada por meio de uma válvula localizada na parte superior da caneta (contra-ângulo laser 2051), conectada ao equipamento por meio de uma fibra óptica.

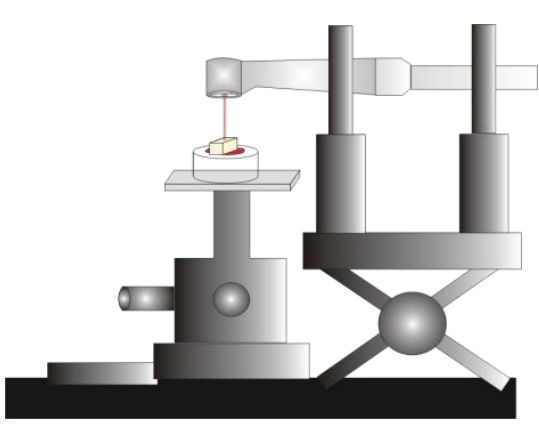

Figura 3 - Irradiação dos espécimes com laser de Er:YAG 
No grupo controle, o preparo cavitário foi realizado com ponta diamantada (\#2096, KG Sorensen, Alphaville, SP, Brasil) em turbina de altarotação (Silent, Dabi Atlante, Ribeirão Preto, Brasil) sob refrigeração constante (Figura 4). A padronização do preparo foi realizada através da Máquina de Preparo Cavitário (MPC, EIQuip, São Carlos, SP, Brasil), na qual o movimento dos eixos é monitorado por relógios digitais que garantem precisão de $0,01 \mathrm{~mm}$ na dimensão das cavidades.

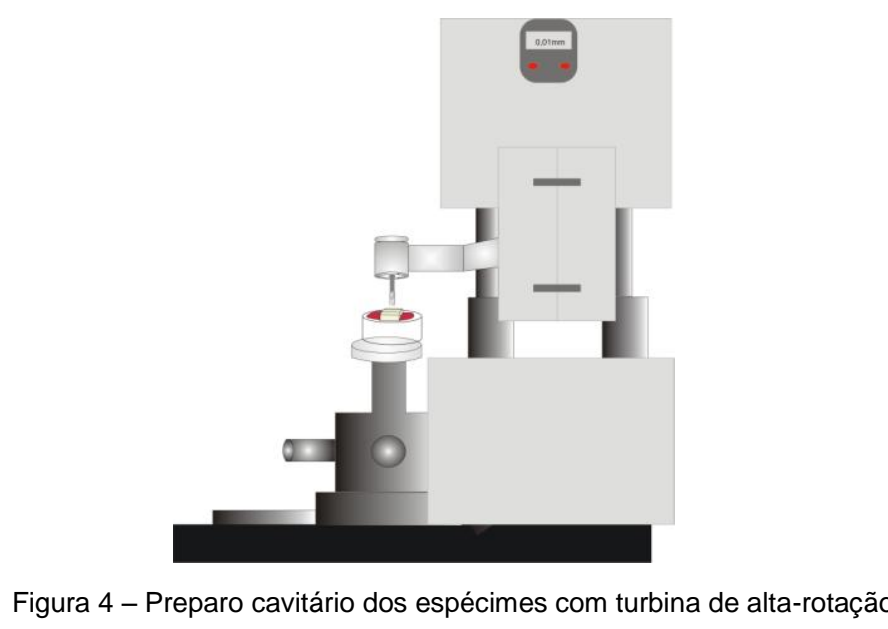

\section{Procedimento restaurador}

Após o preparo cavitário de cada grupo foi realizado o procedimento restaurador conforme as instruções do fabricante. Os espécimes receberam o condicionamento da superfície dental com gel de ácido fosfórico (3M Dental Products, St Paul, MN, USA) a $35 \%$ por 15 segundos. As cavidades foram lavadas pelo mesmo tempo de condicionamento e secas com auxílio de papel absorvente. Posteriormente, os espécimes receberam aplicação de duas camadas do sistema adesivo (Single Bond Adper, 3M Dental Products, St Paul, MN, USA), seguidas de leve jato de ar por 10 segundos a uma distância de $1 \mathrm{~cm}$, para a evaporação do excesso de solvente. Depois disso, foram fotopolimerizadas por 10 segundos, utilizando uma unidade fotoativadora (Jetlite 3000, J Morita, Estados Unidos) (Figura 5). A potência $(\mathrm{mW} / \mathrm{cm} 2)$ do aparelho fotopolimerizador foi monitorada com auxílio de um radiômetro.

As cavidades foram restauradas com resina composta fotopolimerizável (Z250, 3M Dental Products, St Paul, MN, USA), de acordo com a técnica de inserção incremental, sendo cada incremento polimerizado segundo instruções 
do fabricante, através da mesma fonte de unidade fotoativadora descrita acima (Figura 5). A inserção da resina composta foi realizada com auxílio de um estéreo-microscópio sob aumento de 20x, para evitar que excesso de material restaurador fosse depositado na superfície. Os excessos foram removidos com auxílio de uma lâmina de bisturi.

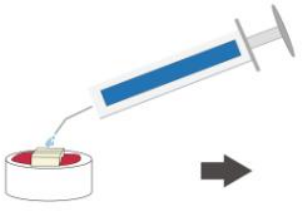

a

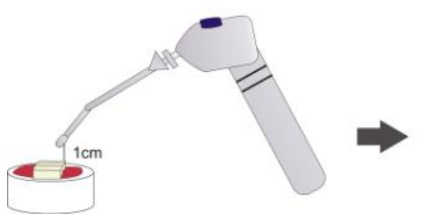

e

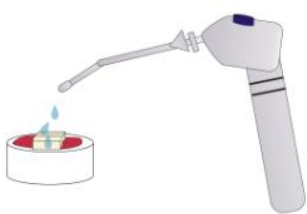

b

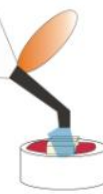

$f$

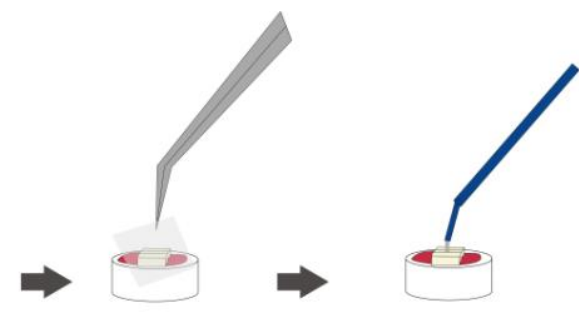

d

Figura 5 - a. Condicionamento ácido; b. Remoção do ácido e lavagem da cavidade; c. Secagem com papel absorvente; d. Aplicação do sistema adesivo; e. Jato de ar; f. Fotopolimerização; g. Inserção da resina composta; h. Fotopolimerização.

Após 24 horas, as restaurações foram polidas com discos Sof Lex (3M Dental Products, St Paul, MN, USA) em ordem decrescente de abrasividade. Após o polimento das restaurações, os espécimes foram imersos em saliva artificial por 24 horas, para estabilizar a troca iônica entre o dente e o meio, padronizando as condições minerais da superfície dos mesmos (HARA et al., 2004).

\section{Desafio Ácido}

Após 24 horas de imersão em saliva artificial, as amostras foram enceradas de modo a delimitar uma área com $12 \mathrm{~mm}^{2}$ (Figura 6). O desafio cariogênico foi realizado através de um modelo in vitro de ciclos de $\mathrm{pH}$ proposto por FEATHERSTONE; O’REALLY; SHARIATY, 1986 e modificado por SERRA; CURY, 1992. 


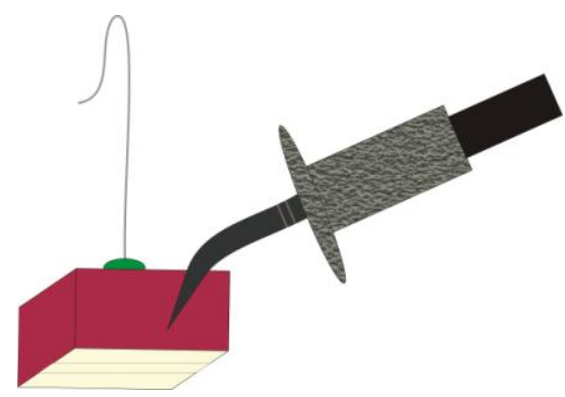

Figura 6 - Enceramento dos espécimes para delimitação da área

Para a realização dos ciclos de $\mathrm{pH}$, cada amostra permaneceu individualmente imersa durante 6 horas em solução desmineralizante. Após 6 horas, foram lavadas com água deionizada, secas com papel absorvente e imersas por 18 horas em solução remineralizante (Figura 7). Os ciclos se estenderam por 14 dias como proposto por FEATHERSTONE; O'REALLY; SHARIATY, 1986. Foram realizados 5 ciclos de des e remineralização e ao final do quinto dia os espécimes foram mantidos na solução remineralizante por 2 dias em estufa a $37^{\circ} \mathrm{C}$. Após 2 dias este procedimento foi repetido, ou seja, mais 5 ciclos de des e remineralização foram realizados e ao final deste período os espécimes foram novamente mantidos em solução remineralizante por 2 dias em estufa a $37^{\circ} \mathrm{C}$.

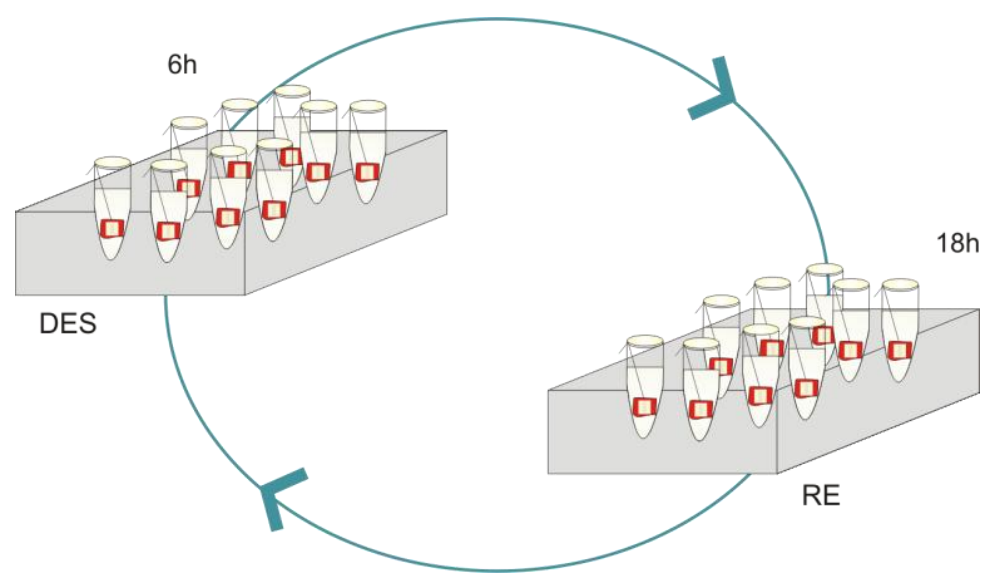

Figura 7 - Ciclos de $\mathrm{pH}$

\section{Leituras de Microdureza}

Após o período de desafio cariogênico, os espécimes foram incluídos em resina acrílica e seccionados longitudinalmente no centro da restauração e, em seguida, posicionados em matriz de teflon com cera fundida e auxílio do paralelômetro, para serem polidos na Politriz giratória refrigerada até se obter 
uma superfície lisa e polida. Após o polimento, uma das hemi-secções foi selecionada para o ensaio de microdureza. As leituras de microdureza foram realizadas no microdurômetro (HMV-2000, Shimadzu Corporation, Japão), com auxílio de um penetrador de diamante para dureza Knoop (KHN).

Foram realizadas três endentações na parede adjacente ao preparo cavitário, distante $30 \mu \mathrm{m}$ da restauração e da superfície do dente e a $100 \mu \mathrm{m}$ de distância uma da outra (Figura 8). A carga empregada foi de $25 \mathrm{~g}$ pelo tempo de 10s. A média dos valores de microdureza obtidos foi empregada na análise estatística.

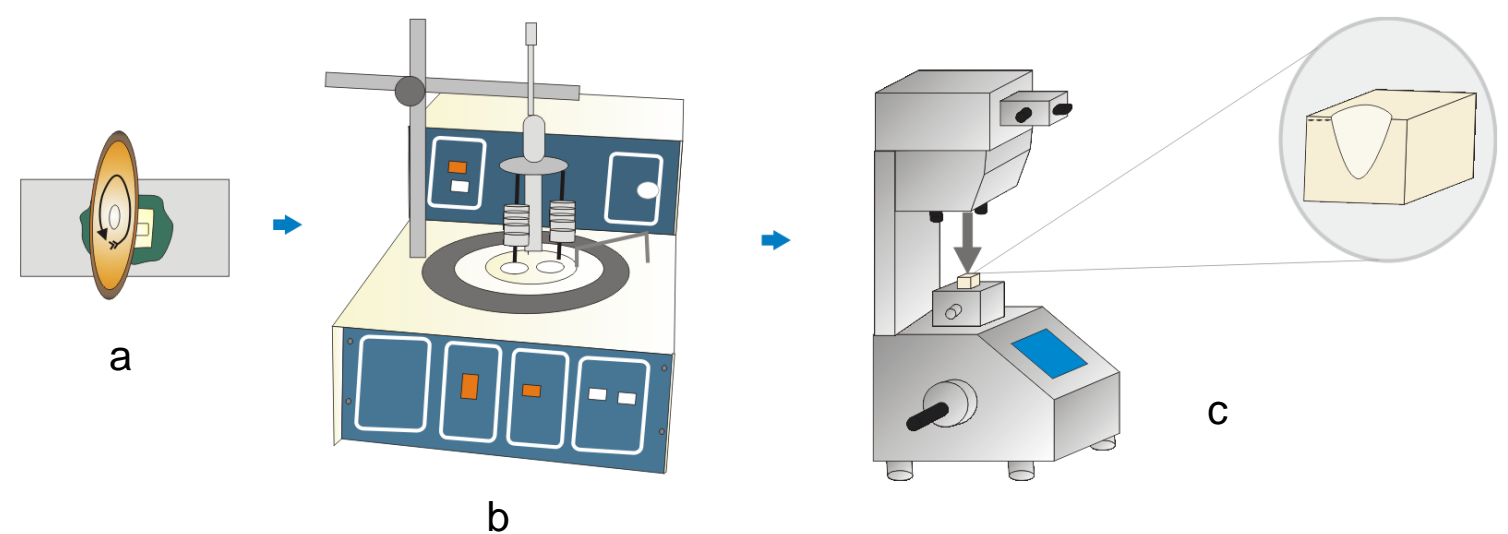

Figura 8 - a. Secção dos espécimes; b. Polimento; c. Leituras de microdureza subsuperficial

\section{Microscopia de luz polarizada}

A outra secção de esmalte foi novamente submetida à máquina de corte para que se obtivesse uma fatia com espessura de $1 \mathrm{~mm}$. Depois disso foi realizado o polimento dos fragmentos com lixas 600 e 1200 até que a espessura atingisse $100 \mu \mathrm{m} \pm 20 \mu \mathrm{m}$ (HARA et al., 2005; PEREIRA et al., 1998; PERIS et al., 2006; CHIMELLO-SOUZA et al., 2009). Após o preparo das amostras estas foram posicionadas em lâminas de vidro para microscopia, embebidas em água deionizada e levadas ao microscópio de luz polarizada (Axiostar Plus, Carl Zeiss, Alemanha) (Figura 9) onde foram obtidas as imagens com auxílio do software Axiovision 4.8 (Carl Zeiss, Alemanha), sob aumento de 10x. A análise das imagens foi qualitativa. 


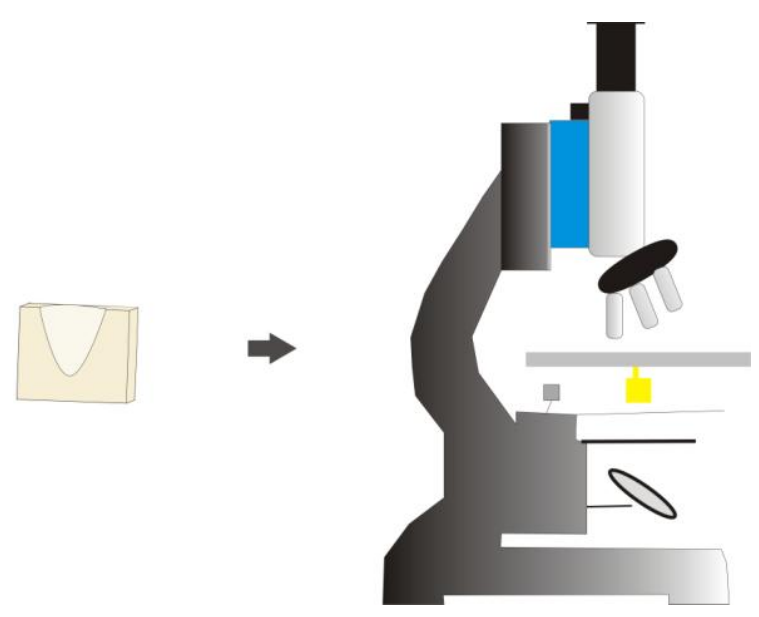

Figura 9 - Microscopia de luz polarizada

\section{Análise estatística}

Os dados obtidos com as leituras de microdureza foram submetidos aos testes de Shapiro Wilk e Cochran que demonstraram haver normalidade e homogeneidade, respectivamente. Feito isso, foi realizada a Análise de Variância e teste de Tukey ao nível de significância de 1\%.

As imagens de microscopia de luz polarizada foram analisadas qualitativamente.

\section{ESTUDO IN SITU}

\section{Delineamento Experimental}

O fator em estudo foi o Preparo Cavitário em 10 níveis, sendo 9 experimentais (I - Laser de Er:YAG - 300mJ/2Hz, 2,0mL/min; II - Laser de Er:YAG - 300mJ/4Hz, 2,0mL/min; III - Laser de Er:YAG - 300mJ/6Hz, 2,0mL/min; IV - Laser de Er:YAG - 300mJ/2Hz, 5,0mL/min; V - Laser de Er:YAG - 300mJ/4Hz, 5,0mL/min; VI - Laser de Er:YAG - $300 \mathrm{~mJ} / 6 \mathrm{~Hz}$, 5,0mL/min; VII - Laser de Er:YAG - 300mJ/2Hz, 8,0mL/min; VIII - Laser de Er:YAG - 300mJ/4Hz, 8,0mL/min; IX - Laser de Er:YAG - $300 \mathrm{~mJ} / 6 \mathrm{~Hz}$, $8,0 \mathrm{~mL} / \mathrm{min}$ ) e 1 controle (preparo cavitário com ponta diamantada em alta rotação). A amostra do experimento apresentava 150 fragmentos de esmalte bovino divididos aleatoriamente nos 10 grupos e entre 15 voluntários que foram considerados blocos estatísticos. O estudo foi do tipo duplo-cego, onde o voluntário e o pesquisador não tomaram conhecimento dos grupos que estavam sendo testados. O delineamento adotado foi o de blocos completos casualizados. 


\section{Seleção dos dentes}

A seleção dos dentes foi realizada como descrita para o estudo in vitro.

\section{Preparo dos fragmentos}

Os dentes foram seccionados como descrito para o estudo in vitro. Cada um dos fragmentos apresentou dimensões de $3 \times 3 \mathrm{~mm}$.

\section{Seleção dos fragmentos}

Os espécimes preparados tiveram suas superfícies laterais polidas em Politriz giratória refrigerada à água. Foram realizadas três leituras de microdureza na lateral dos fragmentos distantes $30 \mu \mathrm{m}$ da superfície e a $100 \mu \mathrm{m}$ uma da outra, estabelecendo-se uma dureza média que permitiu a seleção dos espécimes.

\section{Preparo Cavitário}

Os fragmentos de esmalte bovino foram divididos aleatoriamente entre os grupos de acordo com o preparo cavitário: I - Laser Er:YAG - 300m $/ 2 \mathrm{~Hz}$, 2,0mL/min; II - Laser Er:YAG - 300mJ/4Hz, 2,0mL/min; III - Laser Er:YAG $300 \mathrm{~mJ} / 6 \mathrm{~Hz}, 2,0 \mathrm{~mL} / \mathrm{min}$; IV - Laser Er:YAG - 300mJ/2Hz, 5,0mL/min; V - Laser Er:YAG - 300mJ/4Hz, 5,0mL/min; $\mathrm{VI}$ - Laser Er:YAG - 300mJ/6Hz, 5,0mL/min; VII - Laser Er:YAG - 300mJ/2Hz, 8,0mL/min; VIII - Laser Er:YAG - 300mJ/4Hz, 8,0 mL/min; IX - Laser Er:YAG - 300 mJ $6 \mathrm{~Hz}, 8,0 \mathrm{~mL} / \mathrm{min}$ e X- ponta diamantada em alta rotação. O laser de Er:YAG modelo Kavo Key II foi empregado em uma área delimitada de $2 \mathrm{~mm}^{2}$, até que se obtivesse uma cavidade com profundidade de $1 \mathrm{~mm}$. A aplicação do laser de Er:YAG foi realizada conforme descrita para o estudo in vitro.

No grupo controle, o preparo cavitário foi realizado com ponta diamantada (\#2096, KG Sorensen, Alphaville, SP, Brasil) em turbina de altarotação (Silent, Dabi Atlante, Ribeirão Preto, Brasil), sob refrigeração constante. A padronização do preparo foi realizada como descrito para o estudo in vitro.

\section{Procedimento restaurador}


Após o preparo cavitário de cada grupo, foi realizado o procedimento restaurador conforme descrito no estudo in vitro. Os excessos foram removidos com auxílio de uma lâmina de bisturi. Após 24 horas, as restaurações foram polidas com discos Sof Lex (3M Dental Products, St Paul, MN, USA) em ordem decrescente de abrasividade.

\section{Esterilização dos espécimes}

Após a realização do polimento das restaurações estas foram submetidas à esterilização com óxido de etileno por 72 horas (TORO et al., 2000).

\section{Seleção dos voluntários}

Quinze voluntários, com idade média de 27 anos, 3 do sexo masculino e 12 do sexo feminino, com atividade de cárie ausente porém com existência pregressa da doença e que se incluíam nos critérios de inclusão e não apresentavam os de exclusão foram selecionados (KRASSE, 1988).

\section{Critérios de inclusão}

- Fluxo salivar normal;

- Disponibilidade para seguir a programação estabelecida para o experimento;

- Experiência passada de cárie, porém sem atividade.

\section{Critérios de exclusão}

- Uso de medicamentos que interferem na secreção salivar;

- Radioterapia ou quimioterapia;

- Gravidez ou lactação;

- Alta atividade de cárie ou doença
periodontal;

- Prótese removíveis, aparelho ortodôntico ou placas oclusais;

- Doenças sistêmicas.

Os voluntários selecionados foram esclarecidos quanto ao protocolo a ser empregado no presente estudo e assinaram um termo de consentimento.

\section{Obtenção dos modelos de trabalho}

Após a seleção dos voluntários, estes tiveram suas arcadas superiores e inferiores moldadas com hidrocolóide irreversível (Tropicalgin, Zhermack, 
Alemanha) para a obtenção dos moldes e posteriormente dos modelos de trabalho.

\section{Confecção dos dispositivos palatinos}

Sobre os modelos de trabalho obtidos, foram confeccionados dispositivos palatinos em resina acrílica, contendo duas canaletas (20 x 5mm), sendo uma de cada lado do aparelho (Figura 10). Após a confecção e polimento dos dispositivos, foram realizados os ajustes necessários para promover maior conforto aos voluntários.

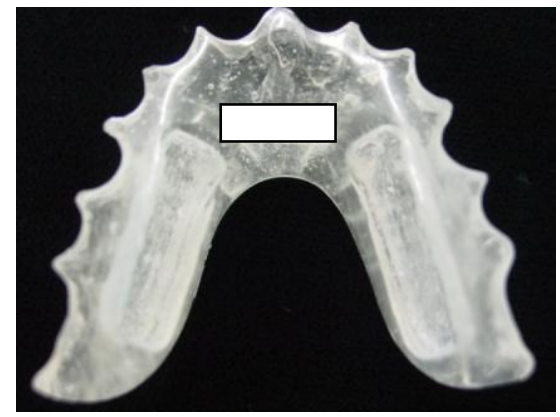

Figura 10 - Dispositivo palatino com as canaletas confeccionadas

\section{Montagem dos fragmentos nos dispositivos palatinos}

De acordo com um sorteio aleatório realizado para cada voluntário, os espécimes restaurados foram inseridos nas canaletas, sendo que foram colocados 5 fragmentos em cada uma delas. Os fragmentos restaurados foram posicionados $1 \mathrm{~mm}$ aquém da margem da canaleta. Após a inserção, estes foram fixados com cera para escultura, com o cuidado de se evitar que a cera atingisse a superfície dos espécimes. Posteriormente à fixação, foi colocada uma tela de algodão, que recobria totalmente os nichos, para permitir o acúmulo de biofilme (BENELLI et al., 1993) (Figura 11).

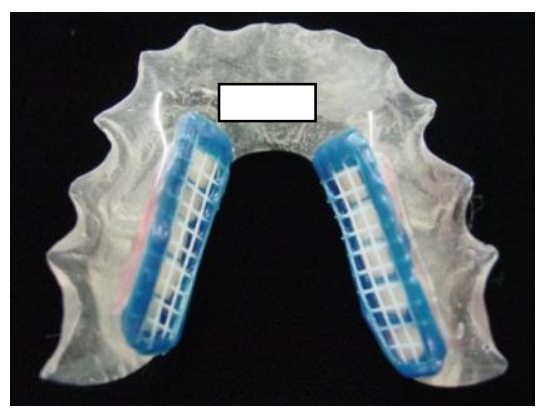

Figura 11 - Dispositivo palatino com os espécimes e a tela de algodão fixados 


\section{Fase clínica}

Antes de iniciar os desafios cariogênicos, os voluntários receberam dentifrício (Gel Dental Colgate, Colgate-Palmolive, Divisão da Kolynos do Brasil Ltda., Osasco, São Paulo, Brasil) e escova dental (Oral-B Indicator 35, Gillette do Brasil Ltda., Manaus, Amazonas, Brasil), padronizados e foram instruídos a utilizá-los 3 dias antes do início da fase clínica (lead-in). Após o lead-in, os dispositivos palatinos foram instalados e os desafios cariogênicos iniciados. Durante a fase clínica, os voluntários receberam solução de dentifrício, na proporção 2:1, para ser gotejada nos fragmentos 3 vezes ao dia (8:00, 11:00, 20:00h), nos mesmos horários em que era realizada a higienização dos dentes naturais. Após 1 minuto o aparelho era enxagüado e colocado novamente em posição. Os voluntários foram também instruídos a gotejar solução de sacarose $20 \%$, seis vezes ao dia nos fragmentos, com intervalo médio de duas horas entre cada uma das aplicações (8:00, 10:00, 12:00, 14:00, 16:00, 18:00h), durante 14 dias seguidos. A duração de cada um dos desafios era de 5 minutos e os dispositivos palatinos não eram enxagüados (PAES-LEME et al., 2004; CHIMELLO-SOUZA et al., 2008; CHIMELLO-SOUZA et al., 2009). Os voluntários foram instruídos a remover o dispositivo palatino previamente à ingestão de alimentos, sendo mantido em posição também durante a noite. A sacarose e as soluções de dentifrícios foram preparadas pela pesquisadora a cada 3 dias e entregue para cada um dos voluntários.

\section{Preparo dos fragmentos para as análises}

Após a finalização da fase clínica do experimento, os espécimes foram individualmente colocados em ependorf e levados ao ultra-som (Ultrasonic Cleaner, T-1440D DG Line, Odontobrás, Brasil) por 1 minuto para remoção do biofilme residual. Posteriormente foram incluídos em resina acrílica para possibilitar a secção dos mesmos.

\section{Leituras de microdureza}

Após a inclusão, os espécimes foram seccionados em cortadeira elétrica de precisão, de modo a se obter um fragmento para a realização das leituras de microdureza subsuperficial. Subseqüentemente, os fragmentos foram polidos com lixas de óxido de alumínio em ordem decrescente de abrasividade 
(\#600 e \#1200) e com suspensão de alumina $0,3 \mu \mathrm{m}$ em politriz giratória refrigerada. Após o polimento, os espécimes foram levados individualmente ao ultrasom por 1 minuto para remoção de debris da superfície polida.

Foram realizadas leituras de microdureza Knoop, a uma distância de 30 $\mu \mathrm{m}$ da superfície do dente, a 30 $\mu \mathrm{m}$ da restauração e $100 \mu \mathrm{m}$ de distância entre elas.

\section{Preparo das amostras para microscopia de luz polarizada}

Os espécimes para a microscopia de luz polarizada foram preparados conforme descrito para o estudo in vitro. Os fragmentos polidos foram embebidos em água destilada para a obtenção das imagens que foram obtidas com auxílio de um microscópio (Jenapol, Carl Zeiss, Alemanha).

\section{Análise estatística}

Após checar a homocedasticidade dos dados pelo teste de Bartlett optou-se pela realização da análise não-paramétrica. O teste de Friedman foi empregado, respeitando-se o delineamento experimental em blocos completos casualizados. Para identificar as diferenças entre os grupos foi realizado o teste de Wilcoxon pareado. 
Resultados 


\section{RESULTADOS}

\section{Estudo in vitro}

\section{a. Ensaio de microdureza}

Observou-se que, independentemente do substrato testado, os espécimes preparados com turbina de alta rotação apresentaram menores médias de microdureza que os preparados com laser de Er:YAG para todos os parâmetros testados $(p<0,05)$, os quais foram semelhantes entre si $(p>0,05)$.

Tabela 1 - Médias de microdureza (KHN) para os substratos humano e bovino preparados com diferentes combinações de parâmetros do laser de Er:YAG ou turbina de alta-rotação

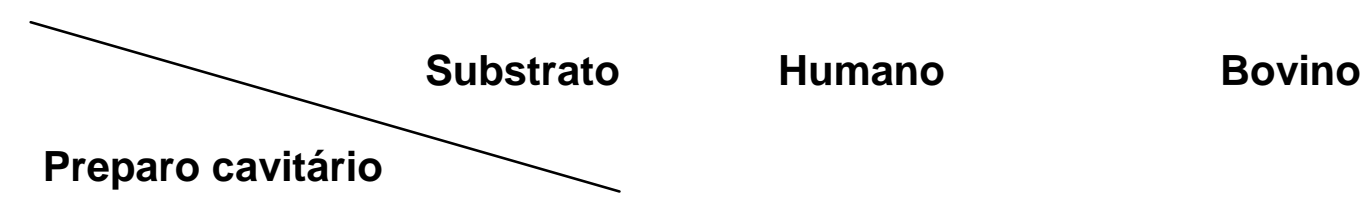

\begin{tabular}{ccc}
\hline Laser de Er:YAG - 2Hz; 2,0mL/min & $281,3 \mathrm{a}$ & $264,6 \mathrm{a}$ \\
Laser de Er:YAG - 2Hz; 5,0mL/min & $301,7 \mathrm{a}$ & $270,5 \mathrm{a}$ \\
Laser de Er:YAG - 2Hz; 8,0mL/min & $264,1 \mathrm{a}$ & $296,7 \mathrm{a}$ \\
Laser de Er:YAG - 4Hz; 2,0mL/min & $292,7 \mathrm{a}$ & $248,7 \mathrm{a}$ \\
Laser de Er:YAG - 4Hz; 5,0mL/min & $295,9 \mathrm{a}$ & $286,3 \mathrm{a}$ \\
Laser de Er:YAG - 4Hz; 8,0mL/min & $288,7 \mathrm{a}$ & $242,5 \mathrm{a}$ \\
Laser de Er:YAG - 6Hz; 2,0mL/min & $259,7 \mathrm{a}$ & $235,7 \mathrm{a}$ \\
Laser de Er:YAG - 6Hz; 5,0mL/min & $276,6 \mathrm{a}$ & $233,1 \mathrm{a}$ \\
Laser de Er:YAG - 6Hz; 8,0mL/min & $282,3 \mathrm{a}$ & $287,9 \mathrm{a}$ \\
Turbina de alta-rotação & $145,9 \mathrm{~b}$ & $117,7 \mathrm{~b}$ \\
\hline
\end{tabular}

*Letras iguais indicam similaridade estatística 


\section{b. Microscopia de luz polarizada}

As imagens obtidas através de microscopia de luz polarizada (Figuras 12, 13, 14, 15 e 16), demonstram uma tendência de haver diferença entre os parâmetros do laser de Er:YAG empregado para o preparo cavitário. O emprego do laser de Er:YAG com a freqüência de pulsos de $2 \mathrm{~Hz}$ parece mais favorável para o controle do desenvolvimento de lesões de cárie adjacente a restaurações, independentemente do fluxo de água empregado. 

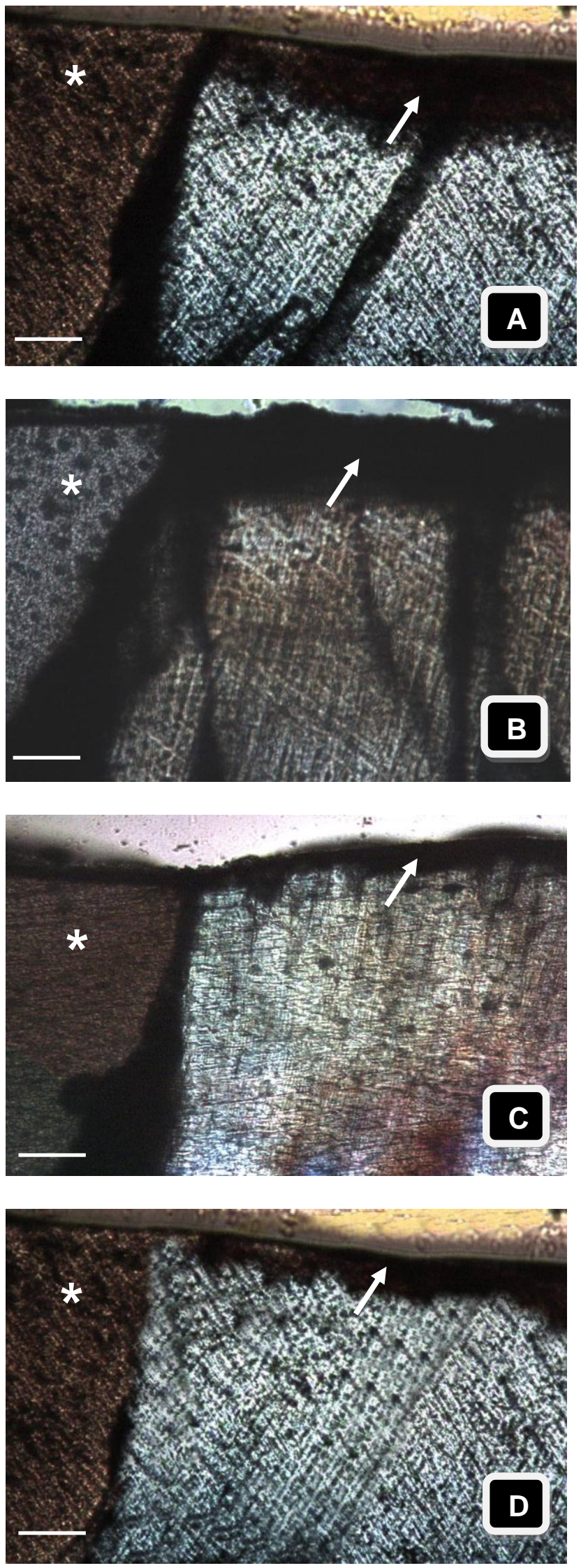

Figura 12 - Microscopia de luz polarizada (A. esmalte humano preparado com turbina de alta-rotação; B. esmalte bovino preparado com turbina de alta-rotação; C. esmalte humano irradiado com laser de Er:YAG - $2 \mathrm{~Hz}$ de freqüência e 2,0mL/min de fluxo de água e D. esmalte bovino irradiado com laser de Er:YAG - $2 \mathrm{~Hz}$ de freqüência e 2,0mL/min de

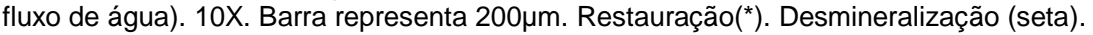



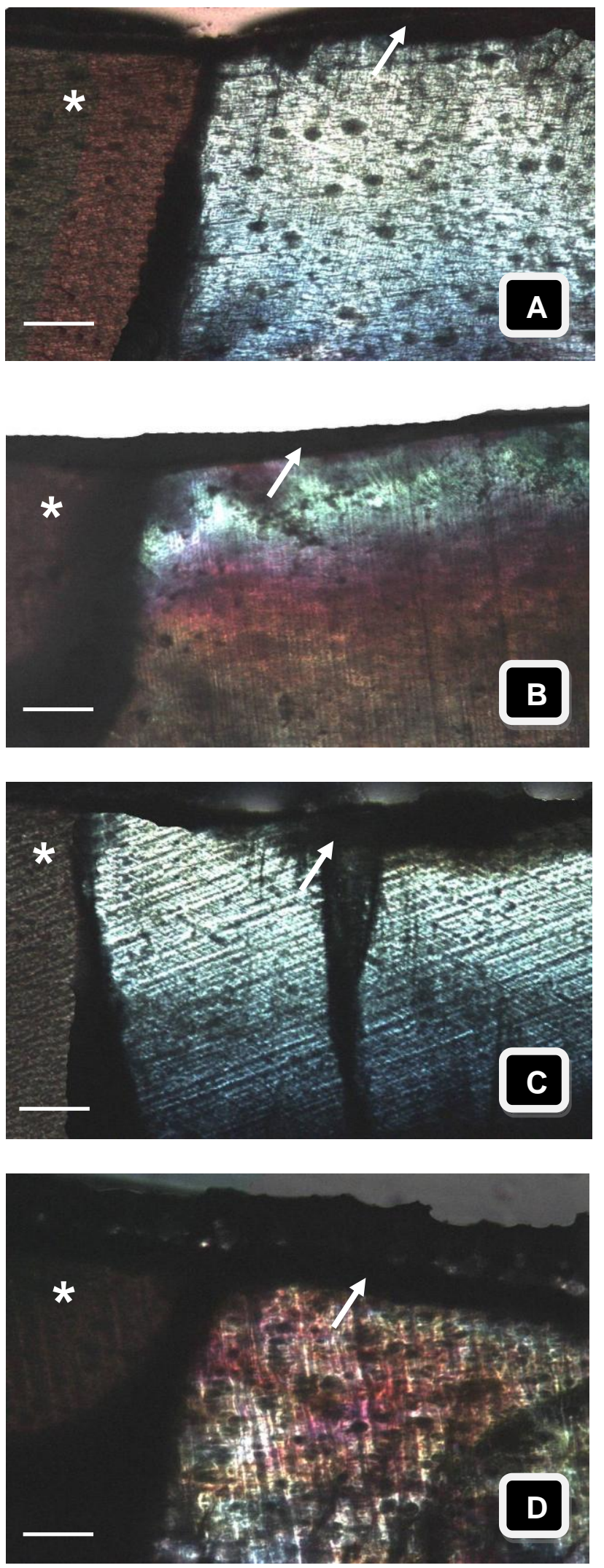

Figura 13 - Microscopia de luz polarizada (A. esmalte humano irradiado com laser de Er:YAG - $2 \mathrm{~Hz}$ de freqüência e $5,0 \mathrm{~mL} / \mathrm{min}$ de fluxo de água; B. esmalte bovino irradiado com laser de Er:YAG - $2 \mathrm{~Hz}$ de freqüência e $5,0 \mathrm{~mL} / \mathrm{min}$ de fluxo de água; C. esmalte humano irradiado com laser de Er:YAG $-2 \mathrm{~Hz}$ de freqüência e $8,0 \mathrm{~mL} / \mathrm{min}$ de fluxo de água e D. esmalte bovino irradiado com laser de Er:YAG - $2 \mathrm{~Hz}$ de freqüência e $8,0 \mathrm{~mL} / \mathrm{min}$ de fluxo de água). 10X. Barra

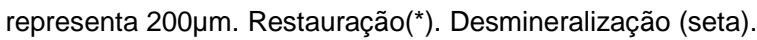



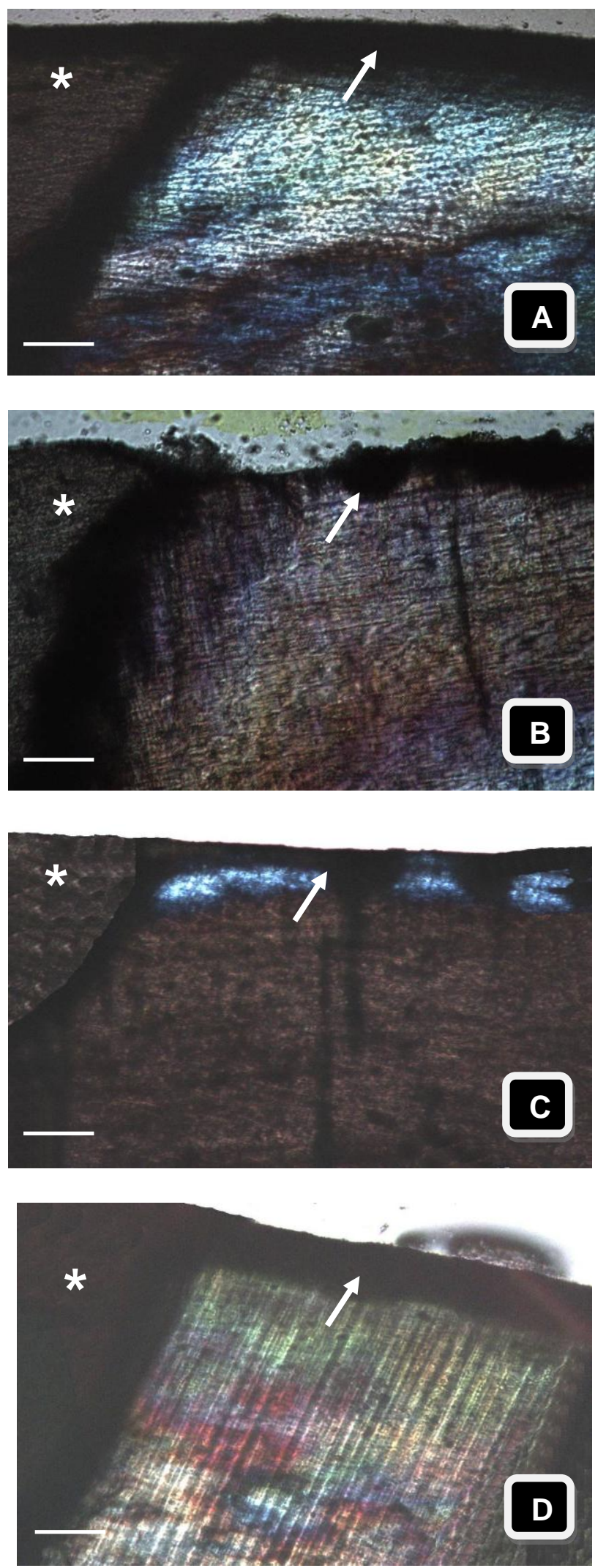

Figura 14 - Microscopia de luz polarizada (A. esmalte humano irradiado com laser de Er:YAG - 4Hz de freqüência e 2,0mL/min de fluxo de água; B. esmalte bovino irradiado com laser de Er:YAG - $4 \mathrm{~Hz}$ de freqüência e 2,0mL/min de fluxo de água; C. esmalte humano irradiado com laser de Er:YAG - $4 \mathrm{~Hz}$ de freqüência e $5,0 \mathrm{~mL} / \mathrm{min}$ de fluxo de água e D. esmalte bovino irradiado com laser de Er:YAG - 4Hz de freqüência e $5,0 \mathrm{~mL} / \mathrm{min}$ de fluxo de água). 10X. Barra representa $200 \mu \mathrm{m}$. Restauração(*). Desmineralização (seta). 

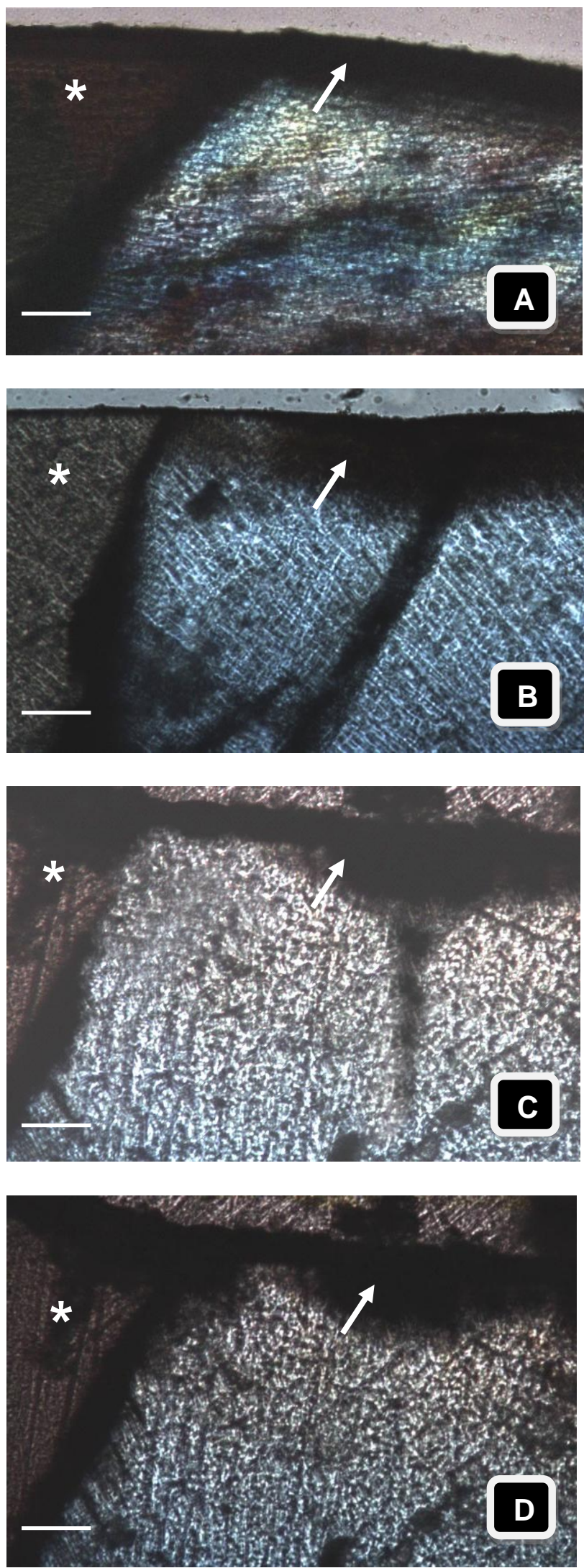

Figura 15 - Microscopia de luz polarizada (A. esmalte humano irradiado com laser de Er:YAG - 4Hz de freqüência e $8,0 \mathrm{~mL} / \mathrm{min}$ de fluxo de água; B. esmalte bovino irradiado com laser de $\mathrm{Er}: Y A G-4 \mathrm{~Hz}$ de frequêencia e $8,0 \mathrm{~mL} / \mathrm{min}$ de fluxo de água; C. esmalte humano irradiado com laser de Er:YAG - $6 \mathrm{~Hz}$ de freqüência e $2,0 \mathrm{~mL} / \mathrm{min}$ de fluxo de água e D. esmalte bovino irradiado com laser de Er:YAG - $6 \mathrm{~Hz}$ de freqüência e 2,0mL/min de fluxo de água). 10X. Barra representa $200 \mu \mathrm{m}$. Restauração(*). Desmineralização (seta). 

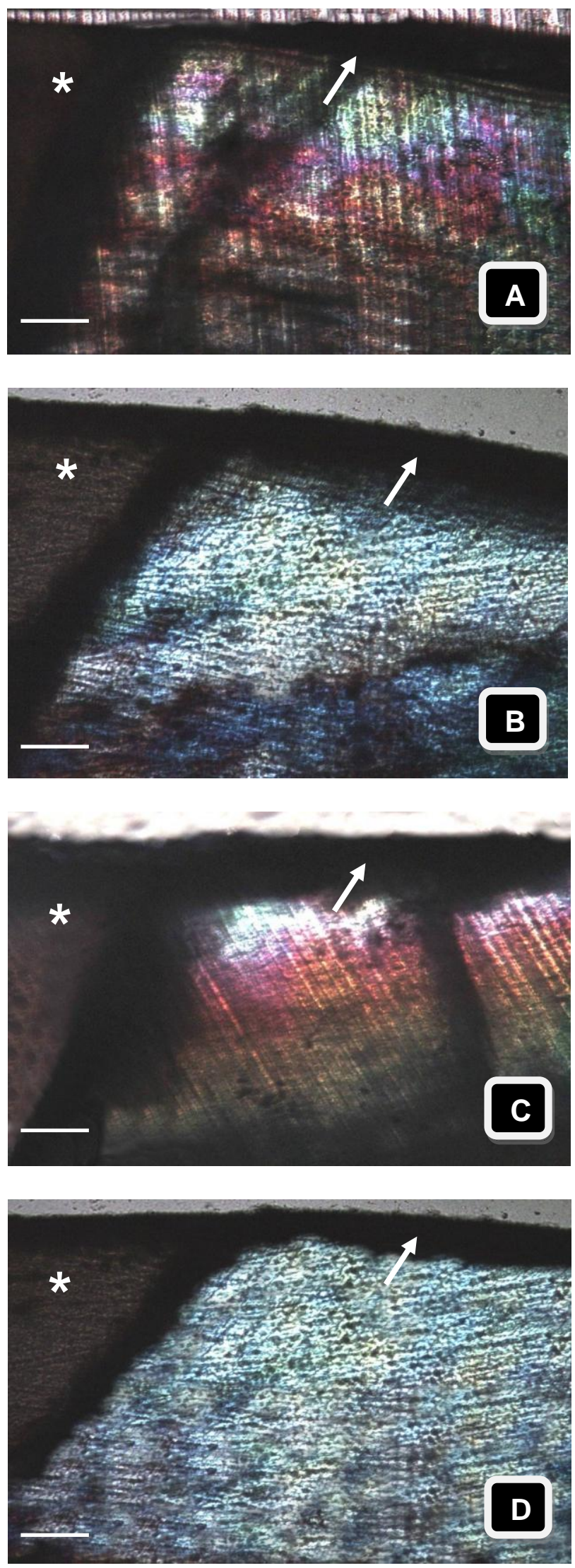

Figura 16 - Microscopia de luz polarizada (A. esmalte humano irradiado com laser de Er:YAG - $6 \mathrm{~Hz}$ de freqüência e $5,0 \mathrm{~mL} / \mathrm{min}$ de fluxo de água; B. esmalte bovino irradiado com laser de Er:YAG - $6 \mathrm{~Hz}$ de freqüência e $5,0 \mathrm{~mL} / \mathrm{min}$ de fluxo de água; C. esmalte humano irradiado com laser de Er:YAG - $6 \mathrm{~Hz}$ de freqüência e $8,0 \mathrm{~mL} / \mathrm{min}$ de fluxo de água e D. esmalte bovino irradiado com laser de Er:YAG - $6 \mathrm{~Hz}$ de freqüência e $8,0 \mathrm{~mL} / \mathrm{min}$ de fluxo de água). 10X. Barra representa $200 \mu \mathrm{m}$. Restauração(*). Desmineralização (seta). 


\section{Estudo in situ}

\section{a. Ensaio de microdureza}

A análise dos dados obtidos demonstrou haver diferença estatística entre os métodos de preparo cavitário empregados com relação as medidas de microdureza. Os resultados estão apresentados no gráfico 1 e tabela 2.

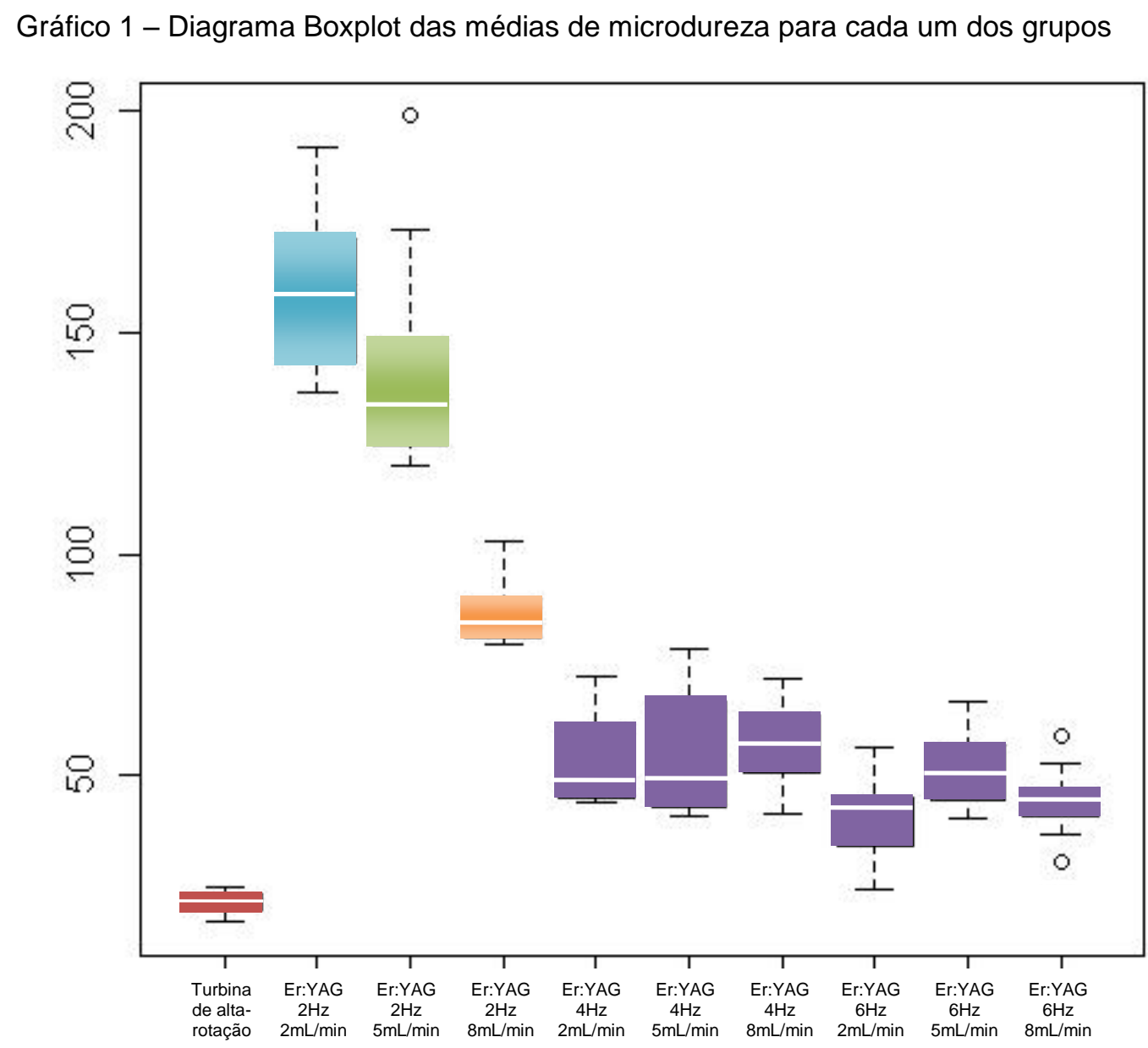

Observa-se que o grupo preparado com laser de Er:YAG com $2 \mathrm{~Hz}$ de freqüência e 2,0mL/min de fluxo de água apresentou a maiores médias de microdureza, seguido por aqueles preparados com laser de Er:YAG com $2 \mathrm{~Hz}$ de freqüência e $5,0 \mathrm{~mL} / \mathrm{min}$ de fluxo de água e laser de $\mathrm{Er}: Y A G$ com $2 \mathrm{~Hz}$ de freqüência e $8,0 \mathrm{~mL} / \mathrm{min}$ de fluxo de água, respectivamente. Os grupos preparados com laser de Er:YAG com as freqüências de $4 \mathrm{~Hz}$ e $6 \mathrm{~Hz}$, com fluxos de água de 2,0, 5,0 e 8,0 $\mathrm{mL} / \mathrm{min}$ apresentaram médias de microdureza menores que os grupos supracitados e com similaridade estatística entre si. Todos os grupos preparados com laser de Er:YAG demonstraram médias de 
microdureza superiores àquele preparado com turbina de alta-rotação, o qual apresentou as menores médias de microdureza.

Tabela 2 - Mediana da microdureza subsuperficial

\begin{tabular}{ccc}
\hline Grupo & Preparo cavitário & Mediana \\
\hline I & Laser de Er:YAG - 2Hz; 2,0mL/min & $152,43 \mathrm{a}$ \\
II & Laser de Er:YAG - 2Hz; 5,0mL/min & $133,08 \mathrm{~b}$ \\
III & Laser de Er:YAG - 2Hz; 8,0mL/min & $91,615 \mathrm{c}$ \\
IV & Laser de Er:YAG - 4Hz; 2,0mL/min & $44,505 \mathrm{~d}$ \\
V & Laser de Er:YAG - 4Hz; 5,0mL/min & $60,665 \mathrm{~d}$ \\
VI & Laser de Er:YAG - 4Hz; 8,0mL/min & $48,355 \mathrm{~d}$ \\
VII & Laser de Er:YAG - 6Hz; 2,0mL/min & $49,035 \mathrm{~d}$ \\
VIII & Laser de Er:YAG - 6Hz; 5,0mL/min & $48,315 \mathrm{~d}$ \\
IX & Laser de Er:YAG - 6Hz; 8,0mL/min & $46,845 \mathrm{~d}$ \\
X & Turbina de alta-rotação & $24,865 \mathrm{e}$ \\
\hline
\end{tabular}

*Letras iguais indicam similaridade estatística

\section{b. Microscopia de luz polarizada}

$\mathrm{Na}$ análise das imagens obtidas através da microscopia de luz polarizada observa-se a confirmação dos resultados observados através do ensaio de microdureza (Figuras 17, 18, 19). Pode-se notar a presença de uma zona de inibição adjacente à restauração nos grupos irradiados com freqüência de $2 \mathrm{~Hz}$, sendo mais evidente nos grupos que foram irradiados com fluxo de água de 2,0 e 5,0mL/min (Figura 17). 

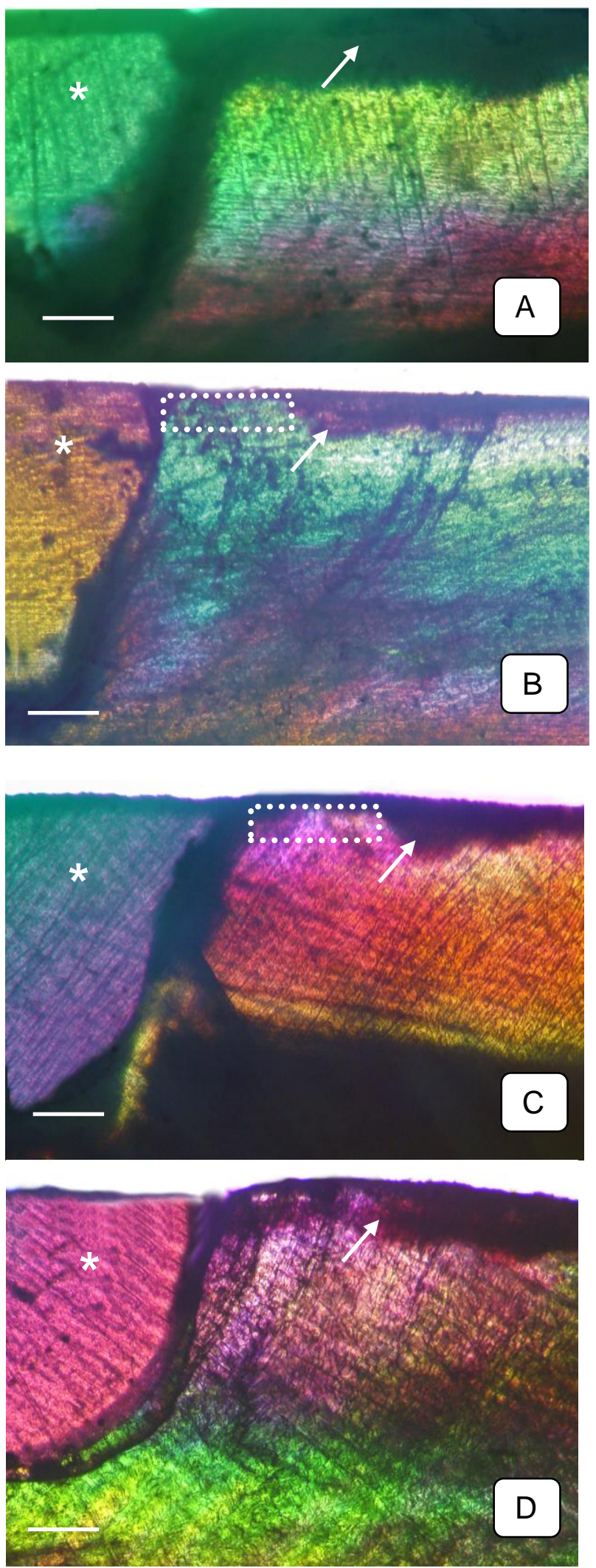

Figura 17 - Microscopia de luz polarizada (A. Preparo cavitário realizado com turbina de alta-rotação e ponta diamantada; B. Preparo cavitário realizado com laser de Er:YAG - $2 \mathrm{~Hz}$ de freqüência de pulsos e $2,0 \mathrm{~mL} / \mathrm{min}$ de fluxo de água; C. Preparo cavitário realizado com laser de Er:YAG - $2 \mathrm{~Hz}$ de freqüência de pulsos e $5,0 \mathrm{~mL} / \mathrm{min}$ de fluxo de água e D. Preparo cavitário realizado com laser de Er:YAG - $2 \mathrm{~Hz}$ de freqüência de pulsos e $8,0 \mathrm{~mL} / \mathrm{min}$ de fluxo de água). 10x. Restauração(*). Desmineralização (seta). Zona de inibição (retângulo). Barra representa 200um. 

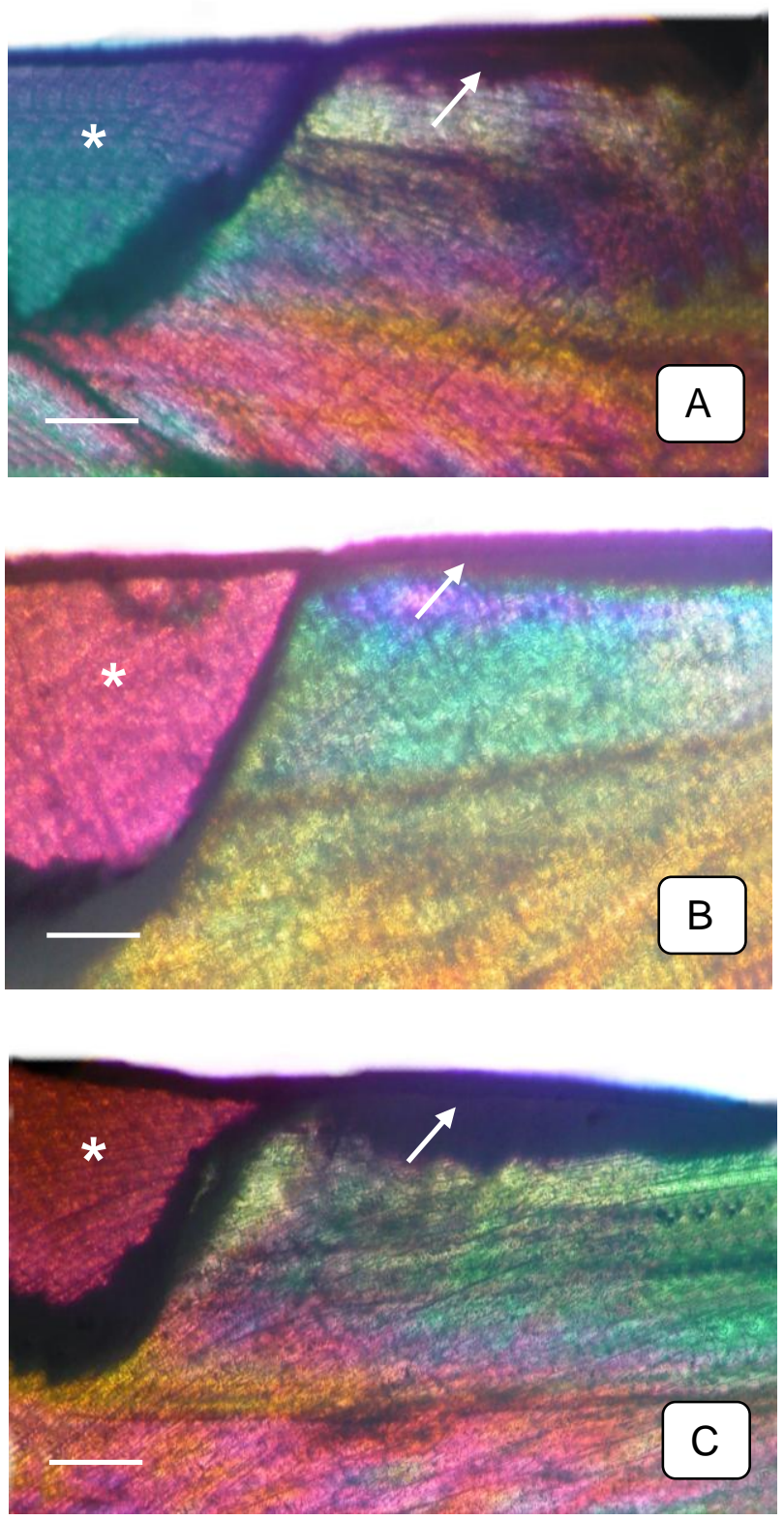

Figura 18 - Microscopia de luz polarizada (A. Preparo cavitário realizado com laser de Er:YAG - 4Hz de freqüência de pulsos e 2,0 $\mathrm{mL} / \mathrm{min}$ de fluxo de água; B. Preparo cavitário realizado com laser de Er:YAG - $4 \mathrm{~Hz}$ de freqüência de pulsos e 5,0mL/min de fluxo de água e C. Preparo cavitário realizado com laser de Er:YAG - $4 \mathrm{~Hz}$ de freqüência de

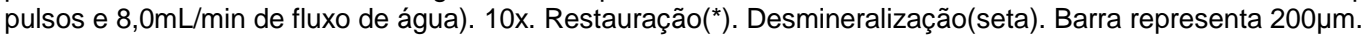



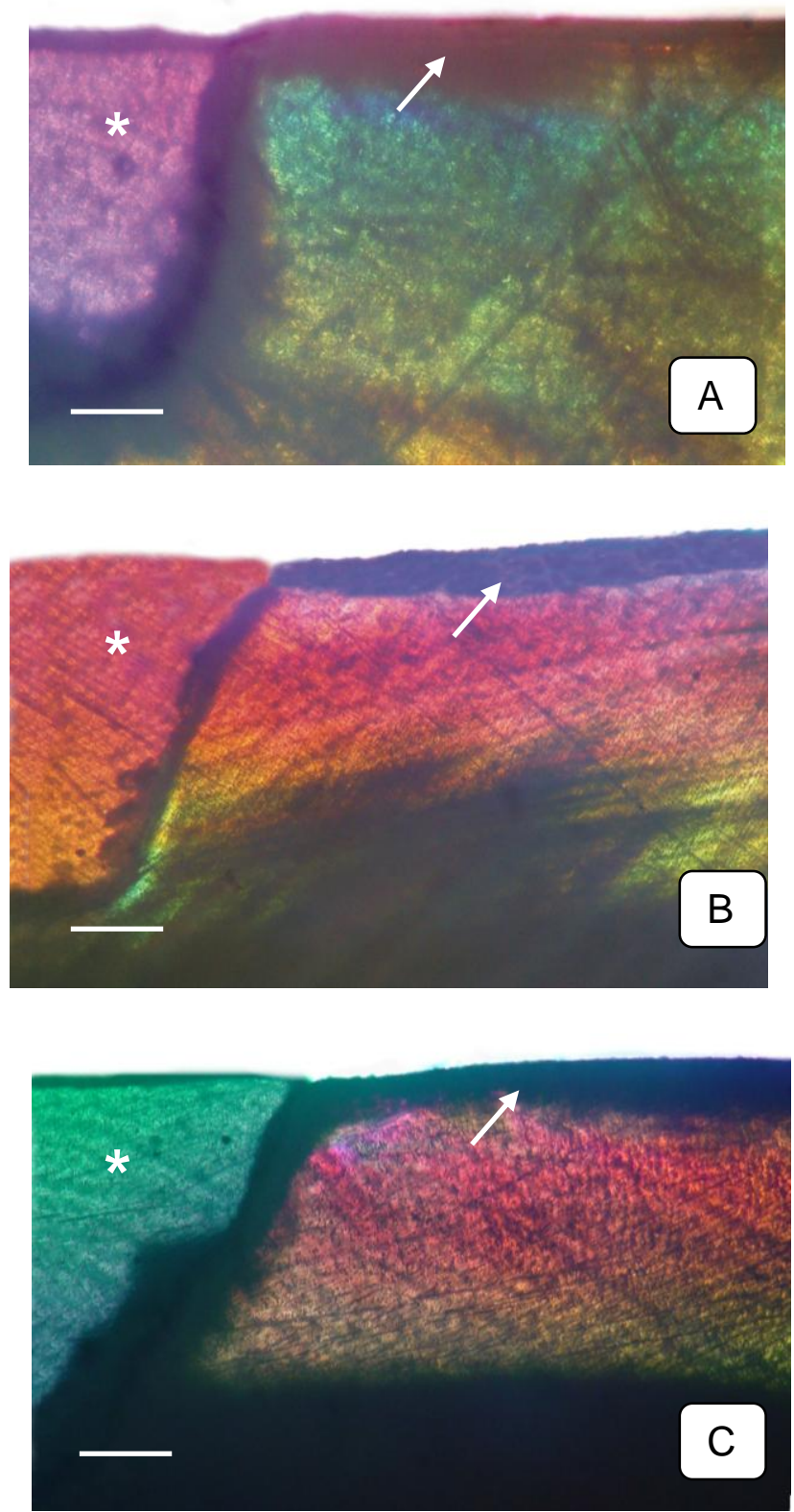

Figura 19 - Microscopia de luz polarizada (A. Preparo cavitário realizado com laser de Er:YAG - 6Hz de freqüência de pulsos e 2,0 mL/min de fluxo de água; B. Preparo cavitário realizado com laser de Er:YAG - $6 \mathrm{~Hz}$ de freqüência de pulsos e 5,0mL/min de fluxo de água e C. Preparo cavitário realizado com laser de Er:YAG - $6 \mathrm{~Hz}$ de freqüência de pulsos e $8,0 \mathrm{~mL} / \mathrm{min}$ de fluxo de água). 10x. Restauração(*). Desmineralização (seta). Barra representa $200 \mu \mathrm{m}$. 
Discussão 


\section{DISCUSSÃO}

Alguns métodos têm sido empregados para avaliar as alterações ocorridas no substrato dental submetido a ciclos de des e remineralização. No presente estudo, foram realizadas medidas de microdureza Knoop longitudinal como variável de resposta quantitativa. Medidas de endentação de microdureza têm sido realizadas para avaliar os efeitos de desafios ácidos desde o primeiro estudo in situ de KOULOURIDES (1966). A medida que os ciclos de des e remineralização vão sendo realizados, as leituras de microdureza podem predizer indiretamente evidências de perda ou ganho mineral (ARENDS; TEN BOSCH, 1992). As leituras de microdureza longitudinal do presente estudo foram realizadas a $30 \mu \mathrm{m}$ da superfície do esmalte, ou seja o mais próximo possível da superfície dental, uma vez que não é possível se obter medidas adequadas até $25 \mu \mathrm{m}$ de profundidade (FEATHERSTONE; ZERO, 1992; ARRENDS; TEN BOSCH, 1992).

Como medida qualitativa complementar aos ensaios de microdureza, as análise em microscopia de luz polarizada têm sido amplamente empregadas (LOBO et al., 2005; LIU; LUI; STEPHEN, 2006; CHU et al., 2007; QUEIROZ et al., 2008). A microscopia de luz polarizada é uma técnica muito sensível utilizada para demonstrar alterações nos tecidos dentais duros. Com relação a des e remineralização, experimentos de birrefringência podem demonstrar qualitativamente a perda e o ganho mineral (ARENDS; TEN BOSCH, 1992) e complementar as análises realizadas através dos ensaios de microdureza.

A complexidade do meio bucal somada aos problemas éticos que envolvem estudos in vivo de doenças bucais como a cárie dental e a doença periodontal tem levado ao desenvolvimento de modelos laboratoriais que simulam o meio bucal in vitro (TANG et al., 2003). Desde sua idealização, os protocolos que envolvem ciclos de $\mathrm{pH}$ vem sendo amplamente empregados em estudos que avaliam o potencial anti-cariogênico de fluoretos, equipamentos e materiais (FEATHERSTONE; O'REALLY; SHARIATY, 1986; SERRA; CURY, 1992; LIU; LIU; STEPHEN, 2006; STEINER-OLIVEIRA et al., 2009; CHEN; HUANG, 2009; PERITO et al., 2009; DELBEM et al., 2009; SOUZA-GABRIEL et al., 2010). Estes modelos consistem na exposição dos substratos, esmalte ou dentina, a ciclos combinados de des e remineralização que visam simular as 
variações dinâmicas de saturação mineral e pH associado com o processo natural do desenvolvimento das lesões de cárie (WHITE, 1995).

No experimento in vitro do presente estudo, foi empregado um modelo de ciclos de $\mathrm{pH}$ para avaliar a influencia de diferentes métodos de preparo cavitário no desenvolvimento de lesões de cárie adjacente à restaurações de resina composta, bem como validar a viabilidade de se empregar substrato bovino em substituição ao humano em estudos que envolvam o uso do laser de Er:YAG.

O esmalte humano é usualmente considerado o substrato de escolha em estudos in vitro e in situ por ser idêntico ou muito próximo dos substratos que se deseja mimetizar. Entretanto, existem muitas desvantagens em se utilizar dentes humanos, especialmente em seu estado natural. Além dos aspectos éticos envolvidos, uma das grandes desvantagens é que dentes humanos são de difícil obtenção, especialmente em quantidade e qualidade suficientes para o desenvolvimento adequado do experimento (MELLBERG, 1992). Além disso, este substrato apresenta elevada inconstância decorrente de desafios cariogênicos prévios ocorridos na cavidade bucal e da variação de idade dos indivíduos, o que o faz com que haja maior variabilidade na resposta aos tratamentos estudados (MELLBERG, 1992).

Frente a estas limitações, o uso do esmalte bovino em substituição ao humano em estudos de cárie envolvendo o emprego do laser de Er:YAG foi validado no estudo in vitro, onde observou-se comportamento similar dos substratos empregados frente aos métodos de preparo cavitário avaliados. Relata-se que a distribuição mineral das lesões de cárie artificial e as alterações estruturais ocorridas em dentes humanos e bovinos é similar (EDMUNDS; WHITTAKER; GREEN, 1988). Um outro detalhe a ser discutido, é que no presente estudo foi empregado substrato humano proveniente de terceiros molares inclusos de pacientes pertencentes a uma mesma faixa etária, na tentativa de se obter melhor padronização da amostra. Tal padronização pode ter sido responsável pelo comportamento similar dos substratos humano e bovino, tanto qualitativo quanto quantitativo. Sabe-se que o esmalte de terceiros molares inclusos apresenta-se mais poroso que o esmalte de dentes irrompidos (MELLBERG, 1992), e tal condição o aproxima da morfologia dos dentes bovinos. 
Após validar o emprego do substrato bovino em experimentos que avaliam o desenvolvimento de lesões de cárie em substratos irradiados com laser de Er:YAG, a análise dos dados obtidos no estudo in vitro demonstrou que, independentemente do substrato testado, os espécimes preparados com turbina de alta rotação apresentaram menores médias de microdureza que os preparados com laser de Er:YAG para todos os parâmetros testados, os quais foram semelhantes entre si. Distintas explicações têm sido sugeridas para explicar o aumento da resistência ácida dos substratos irradiados com o laser de Er:YAG.

Acredita-se que o laser de Er:YAG promove desnaturação parcial da matriz do esmalte, formação de um bloco mineral que retarda a difusão dos ácidos. Tal fato faz com que haja a redução da desmineralização (YING et al., 2004), uma vez que a estrutura cristalina do esmalte faz com que o ácido, antes de reagir e dissolver os cristais de apatita tenha que se difundir através dos espaços interprismáticos e intercristalinos na superfície do cristal, sendo o processo de difusão o principal responsável pela formação da lesão de cárie (FEATHERSTONE, 1983).

Alguns estudos sugerem ainda que a resistência ácida do esmalte esteja relacionada com alterações morfológicas, como a fusão da superfície do esmalte, ocorridas quando da irradiação (HOSSAIN et al., 1999; HOSSAIN et al., 2001; STERN; SOGNNAES; GOODMAN, 1966; TAGAMORI; IWASE, 1995). Porém, tem sido demonstrado que a morfologia superficial do esmalte não necessita ser alterada para reduzir a solubilidade do tecido. Possivelmente alterações químicas e estruturais sejam mais importantes que alterações morfológicas (DELBEM et al, 2003; DA-GUANG et al., 2000; O'BRIEN et al., 1998).

Alterações químicas e estruturais, como perda de água (mais acentuada ao redor de 250 a $300^{\circ} \mathrm{C}$ ), redução do conteúdo total de carbonato e rearranjo dos íons $\mathrm{CO}^{3-}$ (ao redor de 400 a $650^{\circ} \mathrm{C}$ ) são observadas quando o esmalte é submetido à temperaturas entre 100 e $650^{\circ} \mathrm{C}$, o que torna a hidroxiapatita menos solúvel (ROZANIZADEH et al., 1999). Além disso, observa-se aumento progressivo dos íons $\mathrm{OH}^{-}$(chegando a um valor máximo por volta de 300$500^{\circ} \mathrm{C}$ ), e condensação de íons $\mathrm{HPO}_{4}{ }^{2-}$ com conseqüente formação de pirofosfato $\left(200\right.$ a $\left.400^{\circ} \mathrm{C}\right)$, que tem a capacidade de inibir a dissolução dos 
cristais de hidroxiapatita (HIROTA; FURUMOTO, 2002). A decomposição de proteínas ocorre ao redor de $350^{\circ} \mathrm{C}$, e uma leve contração na dimensão do eixo $\alpha$ da apatita é observada aos $250-300^{\circ} \mathrm{C}$ (FOWLER; KURODA, 1986). A formação de metafosfato também pode ser observada, sendo esta estrutura insolúvel em ácidos, por possuir cadeia química longa (HIROTA; FURUMOTO, 2002).

Assim, as alterações teciduais induzidas pelo laser de Er:YAG podem ser moduladas pelo conjunto de parâmetros empregados para a irradiação. Tanto a freqüência de pulsos quanto o fluxo de água empregado quando da irradiação podem interferir na temperatura gerada $e$, conseqüentemente, no calor residual resultante (BURKES et al., 1992; FRIED; RAGADIO; CHAMPION, 2001; GERALDO-MARTINS et al., 2005).

A realização de protocolos de ciclos de $\mathrm{pH}$ como empregado neste estudo, promove uma desmineralização bastante acentuada dos substratos (ARGENTA; TABCHOURY; CURY, 2003). Dentre os diversos modelos empregados para simular lesões de cárie, os mais simples e mais utilizados empregam soluções ácidas tampondas, nas quais os tampões têm a tendência de produzir a erosão da superfície (SERRA; CURY, 1992). Como as leituras de microdureza do estudo in vitro foram realizadas a $30 \mu \mathrm{m}$ da superfície do espécime, essa ação na camada superficial do substrato pode ter mascarado o efeito dos diferentes parâmetros do laser de Er:YAG no desenvolvimento de lesões de cárie adjacentes às restaurações. Através da análise das microscopias de luz polarizada do estudo in vitro, observou-se uma tendência de haver diferença entre os parâmetros empregados e tal possibilidade fez com que fosse delineado o estudo in situ.

Devido à natureza multifatorial da doença cárie, modelos in situ têm sido amplamente empregados para avaliar o desenvolvimento das lesões cariosas em substratos submetidos a distintos tratamentos (CHIMELLO-SOUZA et al., 2008; CHIMELLO-SOUZA et al., 2009; PINTO et al., 2009; GAMEIRO et al., 2009; LIMA et al., 2009; SOUSA et al., 2009). Este tipo de experimento atua como uma ponte entre os estudos clínicos, de difícil controle e estudos laboratoriais, onde se observa uma situação amplamente controlada (ZERO, 1995). As maiores vantagens deste tipo de modelo experimental é a possibilidade de interação do substrato testado com a saliva e o biofilme 
presentes no ambiente oral ao mesmo tempo em que se obtém o controle das variáveis experimentais (ZERO, 1995).

O protocolo experimental empregado baseou-se em estudos prévios in situ (BENELLI et al., 2003; HARA et al., 2003; PAES-LEME et al., 2004; APEL et al., 2005; CHIMELLO-SOUZA et al., 2008; CHIMELLO-SOUZA et al., 2009), com algumas modificações. Neste estudo optou-se pela realização de 6 exposições diárias dos fragmentos de esmalte à sacarose $20 \%$, o que simula a ingestão frequente de açúcar, responsável pelo desenvolvimento das lesões de cárie em pacientes de alto risco (PAES LEME et al., 2004). Além disso, foram realizadas exposições dos fragmentos ao dentifrício fluoretado três vezes ao dia, com intuito de se aproximar o modelo in situ das condições clínicas observadas no desenvolvimento das lesões de cárie. Embora os fragmentos não tenham sido escovados, estes eram gotejados com solução de dentifrício e, posteriormente, enxagüados nos mesmo horários de escovação dos dentes naturais dos voluntários, para que se obtivesse o contato da superfície de esmalte com fluoretos.

Os resultados obtidos com o estudo in situ demonstraram haver diferença entre os parâmetros do laser de Er:YAG empregado para o preparo cavitário quando comparados com a turbina de alta-rotação, conforme observado no estudo in vitro. Além disso, observou-se que a utilização do laser de Er:YAG com $2 \mathrm{~Hz}$ de freqüência de pulsos proporcionou as maiores médias de microdureza adjacentes à restauração. Foi demonstrado que a associação de uma freqüência de $2 \mathrm{~Hz}$ com $2,0 \mathrm{~mL} / \mathrm{min}$ de refrigeração promoveu a menor desmineralização adjacente à restauração, seguida pela associação desta mesma freqüência de pulsos com fluxos de água de 5,0 e 8,0 $\mathrm{mL} / \mathrm{min}$, respectivamente. Observa-se ainda, nas imagens de microscopia de luz polarizada, a presença de uma zona de inibição nos espécimes dos grupos irradiados com $2 \mathrm{~Hz}$, sendo mais evidente naqueles irradiados com fluxo de água de 2,0 e 5,0mL/min. Estudos prévios relatam a modulação da resistência ácida dos substratos dentais quando estes são irradiados sob refrigeração com água (HOSSAIN et al., 2000; YOUNG; FRIED; FEATHERSTONE, 2000). O fluxo de água empregado leva à formação de um filme aquoso na superfície do dente que faz com que parte da energia irradiada nos tecidos-alvo seja consumida para remover essa água depositada e, então, ablacionar o tecido 
(KIM et al., 2003; COLUCCI et al., 2009; COLUCCI et al., 2010). Acredita-se que quando se manteve a mesma freqüência de pulsos de $2 \mathrm{~Hz}$ e se aumentou o fluxo de água, a energia resultante que atingiu os tecidos tenha sido diferente em função da espessura do filme de água formado na superfície e que, conseqüentemente, um maior filme de água tenha se formado quando se empregou $8,0 \mathrm{~mL} / \mathrm{min}$ de fluxo de água.

Possivelmente, a maior incidência de pulsos do feixe laser tenha compensado a formação do filme de água na superfície. Além disso, o aumento da freqüência de pulsos promove maior deposição de calor (KELLER \& HIBST, 1995; FRIED; RAGADIO; CHAMPION, 2001; GERALDO-MARTINS et al., 2005) e este fato poderia explicar a redução no controle da progressão das lesões de cárie quando comparada com os grupos irradiados com $2 \mathrm{~Hz}$ de freqüência. A proteína do esmalte se decompõe entre 350 e 400ㄷ (HOLCOMB et al., 1980) e o efeito de bloco orgânico responsável pelo aumento da resistência à desmineralização é reduzido com a decomposição da matriz orgânica do esmalte (HSU et al., 2000). Provavelmente, os espécimes irradiados com freqüências superiores a $2 \mathrm{~Hz}$ tenham tido parte de sua matriz orgânica decomposta e, conseqüentemente, tenham apresentado uma menor resistência à desmineralização.

De acordo com os resultados obtidos, o laser de Er:YAG empregado para o preparo cavitário mostrou-se viável no controle da progressão de lesões de cárie adjacente a restaurações, sendo esta condição favorecida pelo emprego de um conjunto de parâmetros adequados. Entretanto, com o objetivo de se evitar o desenvolvimento de lesões de cárie secundária, outros aspectos clínicos deverão ser analisados, uma vez que não somente o aumento da resistência ácida tenha sido suficiente para impedir o aparecimento de lesões de cárie adjacente a restaurações de resina composta. Estudos futuros, que busquem minimizar a desadaptação na região da interface adesiva de substratos irradiados com laser de Er:YAG poderiam auxiliar ainda mais na redução do desenvolvimento de lesões de cárie adjacente a restaurações. Além disso, estudos in vivo são necessários para que se possa confirmar os resultados obtidos. 
Conclusões 


\section{CONCLUSÕES}

De acordo com o estudo in vitro pode-se concluir que:

- O substrato bovino constitui uma alternativa ao substrato humano em estudos que avaliem o preparo cavitário realizado com laser de Er:YAG e progressão de lesões de cárie;

- $\quad$ O preparo cavitário realizado com laser de Er:YAG foi capaz de controlar a desmineralização do esmalte adjacente a restaurações e submetido a desafios cariogênicos, independentemente do conjunto de parâmetros empregado.

Baseado no estudo in situ conclui-se que:

- O conjunto de parâmetros empregados para o preparo cavitário influenciou na resistência ácida do substrato irradiado;

- O preparo cavitário realizado com laser de Er:YAG com freqüência de $2 \mathrm{~Hz}$ e fluxo de água de $2 \mathrm{~mL} / \mathrm{min}$ proporcionou maior resistência à desmineralização do esmalte adjacente a restaurações de resina composta. 


\section{Referencias Bibliográficas}




\section{REFERÊNCIAS BIBLIOGRÁFICAS*}

1. AOKI, A.; ISHILAWA, I., YAMADA, T.; OTSUKI, M.; WATANABE, H.; TAGAMI, J.; YAMAMOTO, H. Comparision between Er:YAG laser and conventional technique for root caries treatment in vitro. Journal of Dental Research, v.77, n.6, p.1404-14, 1998.

2. APEL C, MEISTER J, GOTZ H, DUSCHNNER H, GUTKNECHT N. Structural changes in human dental enamel after subablative erbium laser irradiation and its potential use for caries prevention. Caries Research, v. 39, n. 1, p.65-70, 2005.

3. APEL C, MEISTER J, SCHMITT N, GRÄBER HG, GUTKNECHT N. Calcium solubility of dental enamel following sub-ablative Er:YAG and Er:YSGG laser irradiation in vitro. Lasers in Surgery and Medicine, v.20, n. 5, p.337-41, 2002.

4. APEL, C.; SCHÄFER, C.; GUTKNECHT, N. Demineralization of Er:YAG and Er,Cr:YSGG laser-prepared enamel cavities in vitro. Caries Research, v.37, n.1, p.34-7, 2003.

5. ARENDS, J.; TEN BOSCH, J.J. Deminerlization and remineralization evaluation techniques. Journal of Dental Research, v.71, p.924-28, 1992. Special issue.

6. ARGENTA, R.M.O; TABCHOURY, C.P.M.; CURY, J.A. A modified $\mathrm{pH}$-cycling model to evaluate fluoride effect on enamel demineralization. Pesquisa Odontológica Brasileira, v.17, n.3, p.241-6, 2003.

7. BACHMANN, L.; DIEBOLDER, R.; HIBST, R.; ZEZELL, D.M. Changes in chemical composition and collagen structure of dentine tissue after erbium laser irradiation. Spectrochimica Acta. Part A, Molecular and Biomolecular Spectroscopy, v.61, n.11-12, p.2634-9, 2005.

8. BENELLI, E.M.; SERRA, M.C.; RODRIGUES, A.L. JR.; CURY, J.A. In situ anticariogenic potential of glass ionomer cement. Caries Research, v.27, n.4, p.280-4, 1993.

9. BRANTLEY, C.F.; BADER, J.D.; SHUGARS, D.A. NESBIT, S.P. Does the cycle of restoration lead to larger restorations? Journal of American Dental Association, v.126, n.10, p.1407-13, 1995.

10. BURKES JUNIOR, E.J.; HOKE, J.; GOMES, E.; WOLBARSHT, M. Wet versus dry enamel ablation by Er:YAG laser. Journal of Prosthetic Dentistry, v.67, n.6, p.847-51, 1992. 
11. CAIN K, HICKS J, ENGLISH J, FLAITZ C, POWERS JM, RIVES $\mathrm{T}$. In vitro enamel caries formation and orthodontic bonding agents. American Journal of Dentistry, v.19, n.3, p.187-92, 2006.

12. CAVALCANTI, B.N.; LAGE-MARQUES, J.L.; RODE, S.M. Pulpar temperature increases with Er:YAG laser and high-speed handpieces. Journal of Prosthetic Dentistry, v.90, n.5, p.447-51, 2003.

13. CEBALLOS, L.;TOLEDANO, M OSORIO, R.; GARCIA-GODOY, F.; FLAITZ, C.; HICKS, J. Er:YAG laser pre treatament effect on in vitro secondary caries formation around composite restorations. American Journal of Dentistry, v.14, n.1, p.46-49, 2001.

14. CECCHINI, R.C.M.; ZEZELL, D.M.; OLIVEIRA, E.; FREITAS, P.M.; EDUARDO, C.P. Effect of Er:YAG laser on enamel acid resistance: morphological and atomic spectrometry analysis. Lasers in Surgery and Medicine, v.37, n. 5, p.366-72, 2005.

15. CHEN, C.C.; HUANG, S.T. The effects of lasers and fluoride on the acid resistance of decalcified human enamel. Photomedicine and Lasers Surgery, v.27, n.3, p.447-52, 2009.

16. CHIMELLO-SOUZA, D.T.; DE SOUZA, A.E.; CHINELATTI, M.A.; PÉCORA, J.D.; PALMA-DIBB, R.G.; CORONA, S.A.M. Influence of Er:YAG laser irradiation distance on the bond strength of a restorative system to enamel. Journal of Dentistry, v.34, n.3, p.245-51, 2006.

17. CHIMELLO-SOUZA, D.T.; SERRA, M.C.; RODRIGUES-JÚNIOR, A.L.; PÉCORA, J.D.; CORONA, S.A.M. Influence of Er:YAG laser on microhardness of enamel adjacent ro restorations submitted to cariogenic challenge in situ. Photomedicine and Laser Surgery, v.26, n.4, p.379-385, 2008.

18. CHIMELLO-SOUZA, D.T.; SERRA, M.C.; RODRIGUES-JÚNIOR, A.L.; PÉCORA, J.D.; CORONA, S.A.M. Influence of cavity preparation with Er:YAG Laser on enamel adjacent to restorations submitted to cariogenic challenge in situ: a polarized light microscopic analysis. Lasers in Surgery and Medicine, v.40, n.9, p.634-43, 2008.

19. CHU, J.P.; LI, J.Y.; HAO, Y.Q.; ZHOU, X.D. Effect of compounds of Galla chinensis on remineralisation of initial enamel carious lesions in vitro. Journal of Dentistry, v.35, n.5, p.383-7, 2007.

20. COLUCCI, V.; AMARAL, F.L.B.; LUCISANO, M.; PALMA-DIBB, R.G.; PÉCORA, J.D.; CORONA, S.A.M. Influence of water flow rate on shear bond strength of composite resin to Er:YAG cavity preparation. American Journal of Dentistry, v.21, n.2, p.124-8, 2008.

21. COLUCCI, V.; AMARAL, F.L.B.; LUCISANO, M.; PALMA-DIBB, R.G.; PÉCORA, J.D.; CORONA, S.A.M. Water flow on erbium:yttrium- 
aluminum-garnet laser irradiation: effects on dental tissues. Lasers in Medical Science, v.24, n.5, p.811-8, 2009.

22. COLUCCI, V.; AMARAL, F.L.B.; PALMA-DIBB, R.G.; PÉCORA, J.D.; CORONA, S.A.M. Effects of water flow on ablation rate and morphological changes in human enamel and dentin after Er:YAG laser irradiation. American Journal of Dentistry, 2010. In press.

23. CORONA, S.A.M.; BORSATTO, M.C.; PALMA DIBB, RG.; RAMOS, R.P.; BRUGNERA JR. A.; PÉCORA, J.D. Microleakage on class $\mathrm{V}$ resin composite restorations after bur, air-abrasion or Er: YAG laser preparation. Operative Dentistry, v.26, n.5, p.491-7, 2001.

24. CORRÊA-AFONSO, A.M.; PÉCORA, J.D.; PALMADIBB,R.G.Influence of pulse repetition rate on temperature rise and working time during composite filling removal with the Er:YAG laser. Photomedicine and Lasers Surgery, v.26, n.3, p.221-5, 2008.

25. CORRÊA-AFONSO, A.M.; PALMA-DIBB, R.G.; PÉCORA, J.D. Composite filling removal with erbium: yttrium-aluminum-garnet laser: morphological analyses. Lasers in Medical Science, v.25, n.1, p.1-7, 2010.

26. DA-GUANG, Y.; KIMURA, Y.; KINOSHITA, J.I.; MATSUMOTO, K. Morphological and atomic analytical studies on enamel and dentin irradiated by an erbium, chromium: YSGG laser. Journal of Clinical Lasers in Medicine and Surgery, v.18, n.30, p.139-43, 2000.

27. DELBEM, A.C.; CURY, J.A.; NAKASSIMA, C.K.; GOUVEIA, V.G.; THEODORO, L.H. Effect of Er:YAG laser on CaF2 formation and its anticariogenic action on human enamel: An in vitro study. Journal of Clinical Lasers in Medicine and Surgery, v.21, n.4, p.197-201, 2003.

28. DELBEM, A.C; SASSAKI, K.T; VIEIRA, A.E; RODRIGUES, E.; BERGAMASCHI, M.; STOCK, S.R.; CANNON, M.L.; XIAO, X.; DE CARLO, F.; DELBEM, A.C. Comparison of methods for evaluating mineral loss: hardness versus synchrotron microcomputed tomography. Caries Research, v.43, n.5; 359-65, 2009.

29. DOMINICI, J.T.; ELEAZER, P.D.; CLARK, S.J.; STAAT, R.H.; SCHEETZ, J.P. Disinfection/sterilization of extracted teeth for dental student use. Journal of Dental Education, v.65, n.11, p.1278-80, 2001.

30. DOSTALOVÁ, T.; JELINKOVA, H.; KREJSA, O.; HAMAL, H. Evaluation of the surface changes in enamel and dentin due to possibility of thermal overheating induced by Erbium:YAG laser radiation. Scanning Microscoscopy, v.10, n.1, p.285-90, 1996. 
31. EBERHARD, J.; BODE, K.; HEDDERICH, J.; JEPSEN, S. Cavity size difference after caries removal by a fluorescence-controlled Er:YAG laser and by conventional bur treatment. Clinical of Oral Investigation, v.12, n.4, p.311-8, 2008.

32. EDMUNDS, D.H.; WHITTAKER, D.K.; GREEN, R.M. Suitability of human, bovine, ovine tooth enamel for studies of artificial bacterial carious lesions. Caries Research, v.22, n.6, p.327-36, 1988.

33. ELDERTON, R.J.; NUTTALL, N.M. Variation among dentists in planning treatment. British Dental Journal, v. 154, n.12, p.201-6, 1983.

34. ELDERTON, R.J. Ciclo Restaurador Repetitivo. In Kriger L. ABOPREV: Promoção de saúde bucal. $3^{\text {a }}$ edição. 2003. Artes Médicas.

35. FEATHERSTONE, J.D.B.; O'REALLY, M.M.; SHARIATY, M. Enhancement of remineralization in vitro and in vivo. In: Leach AS, editor. Factors relating to demineralization and remineralization of teeth. 1986, p.23-34, Oxford.

36. FEATHERSTONE, J.D.B. Diffusion phenomena and enamel caries development. Cariology Today, International Congress of Zurich, p. 259-68, 1983.

37. FEATHERSTONE, J.D.; RODGERS, B.E. Effect of acetic, lactic and other organic acids on the formation of artificial carious lesions. Caries Research, v.15, n.5, p.377-85, 1981.

38. FEATHERSTONE, J.D.B. Dental Caries: a dynamic disease process. Australian Dental Journal, v.53, n.3, p.286-291, 2008.

39. FEATHERSTONE, J.D.B. TEN CATE, J.M.; SHARIATI, M.; ARENDS, J. Comparison of artificial caries-like lesions by quantitative microradiography and microhardness profile. Caries Research, v.17, n. 5, p.385-91, 1983.

40. FEATHERSTONE, J.D.B. The continuum of dental caries Evidence for a dynamic disease process. Journal of Dental Research, v.83, specila issue, p.39-42, 2004.

41. FEATHERSTONE, J.D.B. The science and practice of caries prevention. Journal of American Dental Association, v.131, p. 887-9, 2000.

42. FEATHERSTONE, J.D.B.; ZERO, D.T. An in situ model for simultaneous assessment of inhibition of demineralization and enhancement of remineralization. Journal of Dental Research, v.71, p.804-810, 1992. Special issue. 
43. FOWLER, B.O.; KURODA, S. Changes in heated and in laser irradiated human tooth enamel and their probable effects on solubility. Calcified Tissue International, v.38, n.4, p.197-208, 1986.

44. FRIED, D.; ASHOURI, N.; BREUNIG, T.; SHORI, R. Mechanism of water augmentation during IR laser ablation of dental enamel. Lasers in Surgery and Medicine, v.31, n.3, p.186-193, 2002.

45. FRIED, D.; RAGADIO, J.; CHAMPION, A. Residual heat deposition in dental enamel during IR laser ablation at 2.79, 2.94, 9.6 and 10.6um. Lasers in Surgery and Medicine, v.29, n.3, p.221-9, 2001.

46. GAMEIRO, G.H.; NOUER, D.F.; CENCl, M.S.; CURY, J.A. Enamel demineralization with two forms of archwire ligation investigated using an in situ caries model--a pilot study. European Journal of Orthodontics, v.31, n.5, p.542-6, 2009.

47. GERALDO-MARTINS, V.R.; TANJI, E.Y.; WETTER, N.U.; NOGUEIRA, R.D.; EDUARDO, C.P. Intrapulpal temperature during preparation with the Er:YAG: an in vitro study. Photomedicine Lasers and Surgery, v.23, n.2, p.182-6, 2005.

48. HARA, A.T.; ANDO, M.; GONZALEZ-CABEZAS, C.; CURY, J.A.; SERRA, M.C.; ZERO, D. T. Protective effect of the dental pellicle against erosive challenges in situ. Journal of Dental Research, v.85, n.7, p. 612-6, 2006.

49. HARA, A.T.; QUEIROZ, C.S.; FREITAS, P.M.; GIANINNI, M.; SERRA, M.C.; CURY, J.A. Fluoride release and secondary caries inhibition in human and bovine root dentine in situ. European Journal of Oral Science, v. 113, n.3, p.245-50, 2005.

50. HARA, A.T.; QUEIROZ, C.S.; GIANNINI, M.; CURY, J.A.; SERRA, M.C. Influence of the mineral content and morphological pattern of artificial root caries lesion on composite resin bond strength. European Journal of Oral Science, v.112, n.1, p.67-72, 2004.

51. HARA, A.T.; QUEIROZ, C.S.; PAES LEME, A.F.; SERRA, M.C.; CURY, J.A. Caries progression and inhibition in human and bovine root dentine in situ. Caries Research, v.37, n.5, p.339-44, 2003.

52. HIBST, R.; KELLER, U. Effects of water spray and repetition rate on temperature elevation during Er:YAG laser ablation of dentin. Lasers in Dentistry, Proceedings of SPIE, Barcelona, v.2623, p.130-44, 1996.

53. HIBST, R.; KELLER, U. Experimental studies of the application of the Er;YAG laser on dental hard substances: I. Measurement of the ablation rate. Lasers in Surgery and Medicine, v.9, n.4, p.338-44, 1989. 
54. HIBST, R. J. Lasers for caries removal and cavity preparation: state of the art and future directions. Journal of Oral Laser Applications v.2, n.4, p.203-211, 2002.

55. HIROTA F, FURUMOTO K. A hypothesis for acquired acid resistance afforded by the laser irradiation. Lasers in Dentistry, 8th International Congress, Yokohama, Japan, p.307-311, 2002.

56. HOLCOMB, D.; YOUNG, R. Thermal decomposition of human tooth enamel. Calcified Tissue International, v.31, n.3, p.189-201, 1980.

57. HOSSAIN, M.; NAKAMURA, Y.; KIMURA, Y.; MITSUHIRO, I.; YAMADA, Y.; MATSUMOTO, K. Acquired acid resistance of dental hard tissues by $\mathrm{CO} 2$ laser irradiation. Journal of Clinical Laser in Medicine and Surgery, v.17, n.5, p.223-6, 1999.

58. HOSSAIN, M.; NAKAMURA, Y.; KIMURA, Y.; YAMADA, Y.; ITO, M.; MATSUMOTO, K. Caries-preventive effect of Er:YAG laser irradiation with or without water mist. Journal of Clinical Laser in Medicine and Surgery, v.18, n.2, p.61-5, 2000.

59.

HOSSAIN M, NAKAMURA $Y$, KIMURA $Y$, YAMADA $Y$, KAWANAKA T, MATSUMOTO K. Effect of pulsed Nd:YAG laser irradiation on acid demineralization of enamel and dentin. Journal of Clinical Laser in Medicine and Surgery, v.19, n.2, p.105-8, 2001.

60. HOSSAIN, M.; NAKAMURA, Y.; YAMADA, Y.; KIMURA, Y.; NAKAMURA, G.; MATSUMOTO, K. Ablation depths and morfhological changes in human enamel and dentin after Er:YAG laser irradiation with or without water mist. Journal of Clinical Laser Medicine and Surgery, v.17, n.3, p.105-109, 1999.

61. HSU, C.; JORDAN, T.; DEDERICH, D.; WEFEL, J. Effects of lowenergy $\mathrm{CO} 2$ laser irradiation and the organic matrix on inhibition of enamel demineralization. Journal of Dental Research, v.79, n.9, p. 1725-30, 2000.

62. JEPSEN, S.; AÇIL, Y.; PESCHEL, T.; KARGAS, K.; EBERHARD, $J$. Biochemical and morphological analysis of dentin following selective caries removal with a fluorescence-controlled Er:YAG laser. Lasers in Surgery and Medicine, v.40, n.5, p.350-7, 2008.

63. KELLER U, HIBST R. Er:YAG laser effects on soft and hard dental tissues. In: Miserandino LJ, Pick RM. Lasers in Dentistry. 1995, Cap. 11, p.161-72, Quintessence.

64. KELLER, U.; HIBST, R. Experimental studies of the application of the Er:YAG laser on dental hard substances:Il. Light microscopic and 
SEM investigations. Lasers in Surgery and Medicine, v.9, n.4, p.345$51,1989$.

65. KIDD, E.A.M.; TOFFENETTI, F.; MJÖR, I.A. Secondary caries. International Dental Journal, v.42, n.3, p.127-138, 1992.

66. KIM, M.E.; JEOUNG, D.J.; KIM, K.S. Effects of water flow on dental hard tissue ablation using Er:YAG laser. Journal of clinical Laser Medicine and Surgery, v.31, n.3, p. 139-144, 2003.

67. KLAUSNER, L.H.; GREEN, T.G.; CHARBENEAU, G.T. Placement and replacement of amalgam restorations: A challenge for the professional. Journal of Dental Research, v.12, n.3, p.105-12, 1987.

68. KLEIN, A.L.L.; RODRIGUES, L.K.A.; EDUARDO, C.P.; NOBRE DOS SANTOS, M.; CURY, J.A. Caries inhibition around composite restorations by pulsed carbon dioxide laser application. European Journal of Oral Science, v.113, n.3, p.239-44, 2005.

69. KORNBLIT, R.; TRAPANI, D.; BOSSÙ, M.; MULLER-BOLLA, M.; ROCCA, J.P.; POLIMENI, A. The use of Erbium:YAG laser for caries removal in paediatric patients following Minimally Invasive Dentistry concepts. European Journal of Paediatric Dentistry, v.9, n.2, p.81-7, 2008.

70. KOULOURIDES, T. Dynamics of tooth surface oral fluid equilibrium. Advances in Oral Biology, v.2, p.149-71, 1966.

71. KRASSE, B. Biological factors as indicators of future caries. International Dental Journal, v.38, n.4, p.219-25, 1988.

72. KRAUSE, F.; BRAUN, A.; LOTZ, G.; KNEIST, S.; JEPSEN, S.; EBERHARD, J. Evaluation of selective caries removal in deciduous teeth by a fluorescence feedback-controlled Er:YAG laser in vivo. Clinical of Oral Investigation, v.12, n.3, p.209-15, 2008.

73. KWON, Y.H.; LEE, J.S.; CHOI, Y.H.; LEE, J.M.; SONG, K.B. Change of enamel after Er:YAG and $\mathrm{CO}_{2}$ laser irradiation and fluoride treatment. Photomedicine and Lasers Surgery, v.23, n.4, p.389-94, 2005.

74. LAGERWEIJI, M.D.; TEN CATE, J.M. Acid susceptibility at various depths of $\mathrm{pH}$-cycled enamel and dentine specimens. Caries Research, v.40, n.1, p.33-7, 2006.

75. LIMA, F,G,; ROMANO, A.R.; CORREA, M.B.; DEMARCO, F.F. Influence of microleakage, surface roughness and biofilm control on secondary caries formation around composite resin restorations: an in 
situ evaluation. Journal of Applied Oral Science, v.17, n.1, p.61-5, 2009.

76. LIPPERT, F.; NEWBY, E.E.; LYNCH, R.J.; CHAUHAN, V.K.; SCHEMEHORN, B.R. Laboratory assessment of the anticaries potential of a new dentifrice. Journal of Clinical Dentistry, v.20, n.2, p.45-9, 2009.

77. LIU, J.; LIU, Y.; STEPHEN, H.C. Optimal Er:YAG laser energy for preventing enamel demineralization. Journal of Dentistry, v.34, n.1, p.62-6, 2006.

78. LIZARELLI, R.F.; MORIYAMA, L.T.; BAGNATO, V.S. Ablation of composite resins using Er:YAG laser - comparison with enamel and dentin. Lasers in Surgery and Medicine, v.33, n.2, p.132-9, 2003.

79. LOBO, M.M.; GONÇALVES, R.B.; AMBROSANO, G.M.; PIMENTA, L.A. Chemical or microbiological models of secondary caries development around different dental restorative materials. Journal of Biomedical Materials Research Part B - Applied Biomaterials, v.74, n.2, p.725-31, 2005.

80. MALTZ, M.; CARVALHO, F. Diagnóstico da doença cárie. In: Krieger L. ABOPREV: Promoção de saúde bucal: Paradigma, Ciência e Humanização. 1999, Cap. 4, $3^{a}$ edição. 1999. Artes Médicas.

81. MATSUMOTO, K.; NAKAMURA, Y.; MAKESI, K.; KIMURA, Y. Clinical dental application of Er:YAG laser for class $V$ cavity preparation. Journal of Clinical Laser Medicine and Surgery, v.14, n.3, p.123-127, 1996.

82. MATSUMOTO, K.; WANG, X.; ZHANG, C.; KINOSHITA, J. Effect of a novel Er:YAG laser in caries removal and cavity preparation: a clinical observation. Photomedicine and Lasers Surgery, v.25, n.1, p.8-13, 2007.

83. MELLBERG, J.R. Hard-tissue substrates for evaluation of cariogenic and anti-cariogenic activity in situ. Journal of Dental research, v.71, p.913-9, 1992. Special issue.

84. MELLBERG, J.R.; LOERTSCHER, K.L. Comparison of in vitro fluoride uptake by human and bovine enamel from acidulated phosphatefluoride solutions. Journal of Dental Research, v.53, n.1, p.64-7, 1974.

85. MJÖR, I.A.; GORDAN, V.V. Failure, Repair, Refurbishing and longevity of restorations. Operative Dentistry; v.27, n.5, p.528-34, 2002. 
86. MJÖR, I.A.; MOORHEAD, J.E.; DAHL, J.E. Reasons for replacement of restorations in permanent teeth in general dental practice. International Dental Journal, v.50, n.6, p.360-6, 2000.

87. MJÖR, I.A. Clinical diagnosis of recurrent caries. Journal of American Dental Association, v.136, n.10, p.1426-33, 2005.

88. O'BRIEN, S.J.; VANGSNESS, C.T.; WHITE, J.M.; WIGDOR, H.A.; KANTOROWITZ, Z.; FEATHERSTONE, J.D.B.; FRIED, D. Caries prevention by $\mathrm{CO} 2$ laser treatment: Dependency on the number of pulses used. Journal of American Dental Association, v.129, n.5, p.585-91, 1998.

89. PAES LEME, A.F.; DALCICO, R.; TABCHOURY, C.P.M.; DEL BEL CURY, A.A.; ROSALEN, P.L.; CURY, J,A. In situ effect of frequent sucrose exposure on enamel demineralization and on plaque composition after APF application and $F$ dentifrice use. Journal of Dental Research, v.83, n.1, p.71-5, 2004.

90. PELAGALLI, J.; GIMBEL, C.B.; HANSEN, R.T.; SWETT, A.; WINN, D.W. Investigation study of the use of Er:YAG laser versus dental drill for caries removal and cavity praparation-phase I. Journal of Clinical Laser Medicine and Surgery, v.15, n.3, p.109-115, 1997.

91. PEREIRA, P.N.R.; INOKOSHI, S.; YAMADA, T.; TAGAMI, J. Microhardness of in vitro caries inhibition zone adjacent to conventional and resin-modified glass ionomer cements. Dental Materials, v.14, n.3, p.179-85, 1998.

92. PERIS, A.R.; MITSUI, F.H.; LOBO, M.M.; BEDRAN-RUSSO, A.K.; MARCHI, G.M. Adhesive systems and secondary caries formation: Assessment of dentin bond strength, caries depth and fluoride release. Dental Materials, v.23, n.3, p.308-16, 2007.

93. PERITO, M.A.; JORGE, A.C.; FREITAS, P.M.; CASSONI, A.; RODRIGUES, J.A. Cavity preparation and influence of restorative materials on the prevention of secondary caries. Photomedicine and Lasers Surgery, v.27, n.5, p.729-34, 2009.

94. PINTO, C.F.; LEME, A.F.; AMBROSANO, G.M.; GIANNINI, M. Effect of a fluoride- and bromide-containing adhesive system on enamel around composite restorations under high cariogenic challenge in situ. Journal of Adhesive Dentistry, v.11, n.4, p. 293,7, 2009.

95. QUEIROZ, C.S.; HARA, A.T.; PAES-LEME, A.F.; CURY, J.A. pHcycling models to evaluate the effect of low fluoride dentifrice on enamel de- and remineralization. Brazilian Dental Journal, v.19, n.1, p.21-7, 2008. 
96. ROHANIZADEH R, LEGEROS RZ, FAN D, JEAN A, DACULSI G. Ultrastructural properties of laser-irradiated and heat-treated dentin. Journal of Dental Research, v.78, n.12, p.1829-35, 1999.

97. SARRETT, D.C. Clinical challenges and the relevance of materials testing for posterior composite restorations. Dental Materials, v.21, n.1, p.9-20, 2005.

98. SCHEIN, M.T.; BOCANGEL, J.S.; NOGUEIRA, G.E.C.; SCHEIN, P.A.L. SEM evaluation of interaction pattern dentin and resin after cavity preparation using Er:YAG laser. Journal of Dentistry, v.31, n.2, p.127135, 2003.

99. SERRA, M.C.; CURY, J.A. The in vitro effect of glass-ionomer cement restoration on enamel subjected to a demineralization and remineralization model. Quintessence International, v.23, n.2, p.143-7, 1992.

100. SILVA-TAGLIAFERRO, E.P.; RODRIGUES, L.K.; SOARES, L.E.; MARTIN, A.A.; NOBRE-DOS-SANTOS, M. Physical and compositional changes on demineralized primary enamel induced by $\mathrm{CO} 2$ Laser. Photomedicine and Lasers Surgery, v.27, n.4, 2009.

101. SOUSA, R.P.; ZANIN, I.C.; LIMA, J.P.; VASCONCELOS, S.M.; MELO, M.A.; BELTRÃOM H,C,; RODRIGUES, L.K. In situ effects of restorative materials on dental biofilm and enamel demineralisation. Journal of Dentistry, v.37, n.1, p.44-51, 2009.

102. SOUZA-GABRIEL, A.E.; COLUCCI, V.; SERRA, M.C.; TURSSI, C.P.; CORONA, S.A.M. Microhardness and SEM after CO2 laser irradiation or fluoride treatment in human and bovine enamel. Microscopy Research and Technique, 2010. In press.

103. STANINEC, M.; MOCHIZUKI, A.; TANIZAKI, K.; FUKUDA, K.; TSUCHITANI, Y. Effect of etching and bonding on recurrent caries in the teeth restored with composite resin. Journal of Prosthetic Dentistry, v.53, n.4, p.521-5, 1985.

104. STEINER-OLIVEIRA, C.; NOBRE-DOS-SANTOS, M.; ZERO, D.T.; ECKERT, G.; HARA, A.T. Effect of a pulsed CO2 laser and fluoride on prevention of enamel and dentine erosion. Archives of Oral Biology, v.21, 2009. In press.

105. STERN, R.H.; SOGNNAES, F.; GOODMAN, F. Laser effect on in vitro enamel permeability and solubility. Journal of American Dental Association, v.73, n.4, p.838-43, 1966. 
106. TAGOMORI, S.; IWASE, T. Ultrastructural change of enamel exposed to a normal pulsed Nd-YAG laser. Caries Research, v.29, n.6, p.513-20, 1995.

107. TANG, G.; HAK-KONG, Y.; CUTRESS, T.W.; SAMARANAYAKE, L.P. Artificial mouth model systems and their contribution to caries research: a review. Journal of Dentistry, v.31, n.3, p.161-171, 2003.

108. THOMAZ RZ, RUBEN JL, DE VRIES J, TEN BOSCH JJ, HUYSMANS MC. Transversal wavelength independent microradiography a method for monitoring caries lesions over time, validated with transversal microradiography. Caries Research, v.40, n.4, p.281-91, 2006.

109. TORO MJ, LUKANTSOVA LL, WILLIAMSON M, ECKERT GJ, DUNIPACE AJ. In vitro fluoride dose-response study of sterilized enamel lesions. Caries Research, v.34, n.3, p.246-53, 2000.

110. VISURI, S.R.; GILBERT, J.L.; WRIGHT, D.D.; WIGDOR, H.A.; WALSH, J.T. Shear strength of composite bonded to Er:YAG laserprapared dentin. Journal of Dental Research, v.75, n.1, p.599-605, 1996.

111. WANG, L.J.; TANG, R.; BONSTEIN, T.; BUSH, P.; NANCOLLAS, G.H. Enamel demineralization in primary and permanent teeth. Journal of Dental Research, v.85, n.4, p.359-63, 2006.

112. WHITE, D.J. The application of in vitro models to research on demineralization and remineralization of the teeth. Advances in Dental Research, v.9, n.3, p. 175-93, 1995.

113. YING D, CHUAH GK, HSU CYS. Effect of Er:YAG laser and organic matrix on porosity changes in human enamel. Journal of Dentistry, v.32, n.1, p.41-6., 2004.

114. YOUNG, D.A.; FRIED, D.; FEATEHRSTONE, J.D.B.; Treating occlusal pit and fissure surfaces by IR laser irradiation. Lasers in Dentistry, VI Proceedings of SPIE, v.3910, p. 247-253, 2000.

115. ZACH, L.; COHEN, G. Pulp response to externally applied heat. Oral Surgery Oral Medicine Oral Pathology, v.19, p.515-30, 1965.

116. ZERO, D.T. Dental caries process. Dental Clinical of North American, v.43, n.4, p.635-64, 1999.

117. ZERO, D.T. In situ caries models. Advances in Dental Research. v.9, n.3, p.214-30, 1995. 